\title{
Northern Hemispheric Interdecadal Variability: A Coupled Air-Sea Mode
}

\author{
A. TIMMERMANN AND M. LATIF \\ Max-Planck-Institut für Meteorologie, Hamburg, Germany \\ R. Voss \\ Deutsches Klimarechenzentrum, Hamburg, Germany
}

A. GRÖTZNER

Max-Planck-Institut für Meteorologie, Hamburg, Germany

(Manuscript received 20 November 1996, in final form 8 September 1997)

\begin{abstract}
A coupled air-sea mode in the Northern Hemisphere with a period of about 35 years is described. The mode was derived from a multicentury integration with a coupled ocean-atmosphere general circulation model and involves interactions of the thermohaline circulation with the atmosphere in the North Atlantic and interactions between the ocean and the atmosphere in the North Pacific.

The authors focus on the physics of the North Atlantic interdecadal variability. If, for instance, the North Atlantic thermohaline circulation is anomalously strong, the ocean is covered by positive sea surface temperature (SST) anomalies. The atmospheric response to these SST anomalies involves a strengthened North Atlantic Oscillation, which leads to anomalously weak evaporation and Ekman transport off Newfoundland and in the Greenland Sea, and the generation of negative sea surface salinity (SSS) anomalies. These SSS anomalies weaken the deep convection in the oceanic sinking regions and subsequently the strength of the thermohaline circulation. This leads to a reduced poleward heat transport and the formation of negative SST anomalies, which completes the phase reversal.

The Atlantic and Pacific Oceans seem to be coupled via an atmospheric teleconnection pattern and the interdecadal Northern Hemispheric climate mode is interpreted as an inherently coupled air-sea mode. Furthermore, the origin of the Northern Hemispheric warming observed recently is investigated. The observed temperatures are compared to a characteristic warming pattern derived from a greenhouse warming simulation with the authors' coupled general circulation model and also with the Northern Hemispheric temperature pattern associated with the 35-yr climate mode. It is shown that the recent Northern Hemispheric warming projects well onto the temperature pattern of the interdecadal mode under consideration.
\end{abstract}

\section{Introduction}

Interdecadal climate variability is considered to be important in masking the greenhouse warming signal in the present climate record. Hence, it is necessary to understand the mechanisms that generate interdecadal climate variability, particularly in the Northern Hemisphere.

A very important goal of climate research is the identification of climate modes and the understanding of the underlying physical processes. Recently, strong scientific interest has focused on the detection of decadal to secular climate timescales in observational records by means of sophisticated mathematical techniques. Schle-

Corresponding author address: Dr. Axel Timmermann, MaxPlanck-Institut für Meteorologie, Bundesstr. 55, 20146 Hamburg, Germany.

E-mail: timmermann@dkrz.de singer and Ramankutty (1994) perform a singular spectrum analysis of the detrended surface temperature record for several geographical locations over the period of 1858-1992. In the North Atlantic region their analysis yields an oscillation of 76 years. Recently, Mann et al. (1995) performed a multivariate singular value decomposition in the frequency domain of historical and climate proxy records, and evidence is reported for interdecadal and century-scale oscillations. A wavelet analysis of the Northern Hemispheric surface temperature record (Lau and Weng 1995) reveals a timescale of 35-60 years.

The available observations are too sparse to identify the mechanisms that lead to long-term climate changes. However, it is known from paleoclimatology (Broecker et al. 1985; Duplessy et al. 1992) and from model simulations (e.g., Maier-Reimer and Mikolajewicz 1989; Mikolajewicz and Maier-Reimer 1990; Mysak et al. 1993; Winton and Sarachik 1993; Delworth et al. 1993; 
Weaver and Sarachik 1991; Weaver et al. 1993, Weaver et al. 1994; Greatbach and Zhang 1994) that long-term variability and abrupt climate changes (e.g., Manabe and Stouffer 1995; Schiller et al. 1996) in the climate system may originate from changes in the thermohaline circulation (THC). In this context North Atlantic deep water (NADW) formation plays a crucial role. One prominent example of such a climate change in this century was the great salinity anomaly (GSA) - a freshwater anomaly that originated in the Greenland-Iceland-Norway (GIN) Sea in the late 1960s and moved with the East Greenland Current southward. It passed the regions of deep water formation, reducing the deep water formation temporarily (Lazier 1988), and its trajectory turned northeastward in 1971-72. The GSA supports the idea that atmosphere-ocean interactions north of $50^{\circ} \mathrm{N}$ play a crucial role in the generation of interdecadal variability as suggested by Dickson et al. (1975) and Dickson et al. (1988). Dickson et al. (1975) and Dickson et al. (1988) argue that a persistent intensification of northerly winds over the Greenland Sea led to an increased injection of polar waters into the East Greenland Current. This was accompanied also by a shift in the sea-ice conditions (see Mysak et al. 1990), contributing significantly (Häkkinen 1993) to the polar freshwater excess during the GSA. An interdecadal feedback loop explaining the GSA was proposed by Wohlleben and Weaver (1995), which involves the Labrador Sea convection, the subpolar gyre, the atmosphere, and the freshwater transport through the Fram Strait. This mechanism is supported by observations and in particular by the conditions associated with the GSA. The feedback loop is based on the idea that on interdecadal timescales the atmosphere responds to sea surface temperature (SST) anomalies in the subpolar gyre system. Our study follows the same philosophy.

Further evidence for the existence of interdecadal variability is reported by Bjerknes (1964). He describes a climate shift between the late 1890s and the mid-1920s in the North Atlantic. The positive SST trend observed during this period, with maximum anomalies at about $40^{\circ} \mathrm{N}$, is explained by a strengthened atmospheric circulation that stimulated the subtropical ocean gyre. However, the physics of the long-term temperature fluctuations within the Gulf Stream cannot be explained sufficiently in this study. On interannual timescales, which we shall not address here, the wind speed south of $50^{\circ} \mathrm{N}$ and the SSTs are negatively correlated, confirming that interannual variability in the North Atlantic is determined by air-sea flux variations. On the other hand, on interdecadal timescales the correlation is positive, indicating that ocean dynamics (in particular the dynamics of the subtropical and subpolar gyres) are important.

Bjerknes's (1964) ideas are somewhat supported by the analysis of a century-long SST dataset by Kushnir (1994). However, Kushnir (1994) argues that the THC rather than the ocean gyres plays the important role for the North Atlantic interdecadal variability. This is underscored by the fact that maximal SST anomalies can be found in the regions of NADW formation (the northwest Atlantic and GIN Seas). Thus, active coupling between the atmosphere and the THC may be a crucial feature of the interdecadal variability in the North Atlantic. Deser and Blackmon (1993) discuss on the basis of a 90 -yr dataset that the interdecadal sea level pressure (SLP) pattern leads to a damping of the corresponding extratropical SST anomalies, which is in agreement with Kushnir's findings. This was also Bjerknes's (1964) argument to attribute the generation of interdecadal variability to ocean dynamics, with the atmosphere responding to changes in the ocean circulation.

Regarding the physical origin of the interdecadal variability, it has not been clarified yet whether the THC [as proposed by Delworth et al. (1993) analyzing a multicentury coupled general circulation model (CGCM) integration] or the wind-driven ocean circulation or both provide the memory for interdecadal oscillations. In particular, it was argued by Latif and Barnett (1994) and by Grötzner et al. (1998) that decadal variability in the North Pacific and North Atlantic Oceans can be generated by an unstable interaction between the atmosphere and the wind-driven subtropical ocean gyres. One should note, however, that a restoring to observed climatology north of $60^{\circ} \mathrm{N}$ damps the role of the THC in their coupled model.

To separate the interdecadal fluctuations from the greenhouse warming signal, Hegerl et al. (1996) calculate projections of observed 15-, 20-, and 30-yr trends onto a fingerprint pattern, which carries the characteristic greenhouse warming signal, as inferred from greenhouse warming simulations with CGCMs in an optimized way. The optimal fingerprint (Hasselmann 1993) consists of a first-guess greenhouse pattern rotated in the direction of maximum signal-to-noise ratio. One of its characteristics is a relative cooling in the North Atlantic, with maximum cooling around $40^{\circ}-50^{\circ} \mathrm{N}$. This is the region that exhibited remarkable variability on long timescales in Bjerknes's (1964) analysis. The projection (called detection variable) of the observed 30$\mathrm{yr}$ trends onto the optimal fingerprint leaves the 95\% confidence limit just for a few years around 1945 and again around 1990, as shown in Hegerl et al. (1996). This means that during the 1940s one could have claimed the greenhouse warming to be detected with almost the same statistical probability as today. The misidentification in the 1940s might be due to incorrect estimation of the background "noise" consisting of internal variability and external effects.

The aim of our study is to shed light on the role of the atmosphere-ocean interactions on interdecadal timescales. Our attention will be focused on the physical mechanisms that lead to interdecadal oscillations in the Northern Hemisphere and, in particular, in the North Atlantic region.

The paper is organized as follows. Section 2 is devoted 
to the description of the coupled model, its simulation of the mean state, and variability. In section 3 we analyze the simulated Northern Hemispheric variability with spectral methods in order to identify the characteristic timescales in our model simulation. The physical mechanism that leads to the interdecadal oscillations in the Atlantic is described in section 4. In section 5 we discuss the panoceanic connection between the Atlantic and $\mathrm{Pa}$ cific Oceans. In section 6 we discuss the role of the interdecadal climate mode in masking the greenhouse warming signal. The paper concludes with a summary and discussion of the results in section 7 .

\section{Model description}

Our analysis is based on a 700-yr control integration with the coupled atmosphere-ocean model ECHAM-3/ LSG. The model consists of the atmospheric GCM ECHAM-3, the Hamburg version of the European Centre for Medium-Range Weather Forecasts operational weather forecasting model (see Roeckner at al. 1992), and the ocean model LSG (large-scale geostrophic) (Maier-Reimer et al. 1993). ECHAM-3 is a global loworder spectral model with a triangular truncation at wavenumber 21 (T21) and 19 levels in the vertical. This corresponds to a horizontal resolution of about $5.6^{\circ} \times$ $5.6^{\circ}$.

The LSG ocean model neglects nonlinear momentum advection. This model provides an appropriate representation of slow ocean modes only. It has 11 vertical levels and is integrated using a fully implicit numerical method on an E grid with an effective horizontal resolution of approximately $4^{\circ} \times 4^{\circ}$. A thermodynamic sea-ice model is included in the LSG model. To avoid climate drift in the coupled mode, the flux correction technique (Sausen et al. 1988) is applied, which is equivalent to coupling both subsystems by their individual flux anomalies relative to their equilibrium states. The ECHAM-3/LSG model has been used in a number of climate change and response experiments (e.g., Hasselmann et al. 1995; Cubasch et al. 1997; Schiller et al. 1997). Further details about the model and the coupling strategy can be found in Voss et al. (1998).

Figure 1 displays the mean temperature and salinity fields averaged over all 700 years of the detrended control run at 25- and 75-m depth (first and second ocean levels, respectively). The mean temperature and salinity fields are simulated reasonably well at both depths, as expected when flux corrections (Sausen et al. 1988) are applied. However, a comparison with the Levitus (1982) climatology reveals that the temperature structure of the Gulf Stream is rather broad in our model. South of $30^{\circ} \mathrm{N}$ the isotherms are too zonal as compared to the observations. This feature is associated with an overestimation of the subpolar gyre in our model as compared to the subtropical gyre (Fig. 3). Thus, we expect that the physics of the interdecadal climate mode identified in this study might be biased toward the dominant role of the subpolar gyre in our model.

The regions of oceanic convection in our model are shown in Fig. 2, which displays the mean potential energy loss by convection.

In the coupled model, deep convection takes place south of Greenland and in the GIN Sea. Among other mechanisms the convection triggers the THC, which plays a crucial role in the oceanic heat transport between low and high latitudes and may therefore serve as an important component for the generation of long-term variability. The mean circulation in our coupled model can be inferred from Fig. 3. The Gulf Stream has a maximum net mass transport of about $60 \mathrm{~Sv}$ in this model, while observational estimates are of the order of about $150 \mathrm{~Sv}$. It is likely that this underestimation is mainly due to the coarse resolution. The mean of the meridional streamfunction in the Atlantic is shown in Fig. 4, where positive values of the meridional streamfunction stand for a clockwise circulation. The meridional overturning shows an outflow of NADW of about $18 \mathrm{~Sv}$ at $30^{\circ} \mathrm{S}$ and an inflow of Antarctic Bottom Water of about 6-8 Sv into the North Atlantic. Thus, the coupled model used here reproduces the principal features of the North Atlantic THC in a satisfying manner. The simulated mean atmospheric conditions are almost identical to those simulated by the uncoupled atmosphere model (Roeckner et al. 1992). To show that the variability also is simulated reasonably well by the coupled model, we display in Fig. 5 the standard deviations of detrended North Atlantic SST anomalies (based on annual means) as obtained from observations taken (a) from the Global Ice and Sea Surface Temperature (GISST) dataset of the United Kingdom Meteorological Office (UKMO) and (b) from our 700-yr CGCM integration. The two patterns correspond reasonably well to each other, which gives us confidence that the principal feedbacks in the North Atlantic region are simulated correctly.

However, note that the flux correction technique used in our coupled model might have an effect on the climate variability as far as nonlinearities in the system becoming important. For further information on this subject the reader is referred to a number of recent studies exploring the effect of flux corrections (Nakamura et al. 1994; Marotzke and Stone 1995; Cai et al. 1997) on climate feedback. However, a detailed analysis regarding the influence of the flux correction technique on the simulated climate variability in our model is far beyond the scope of this study. ${ }^{1}$ On the other hand, state-of-theart CGCMs integrated without flux corrections still have

\footnotetext{
${ }^{1}$ Note that although the flux correction technique is used in our 700-yr integration, there is a strong climate drift in the Antarctic Ocean. Almost all the Antarctic sea ice is melted within the first 150 years of the coupled model integration.
} 

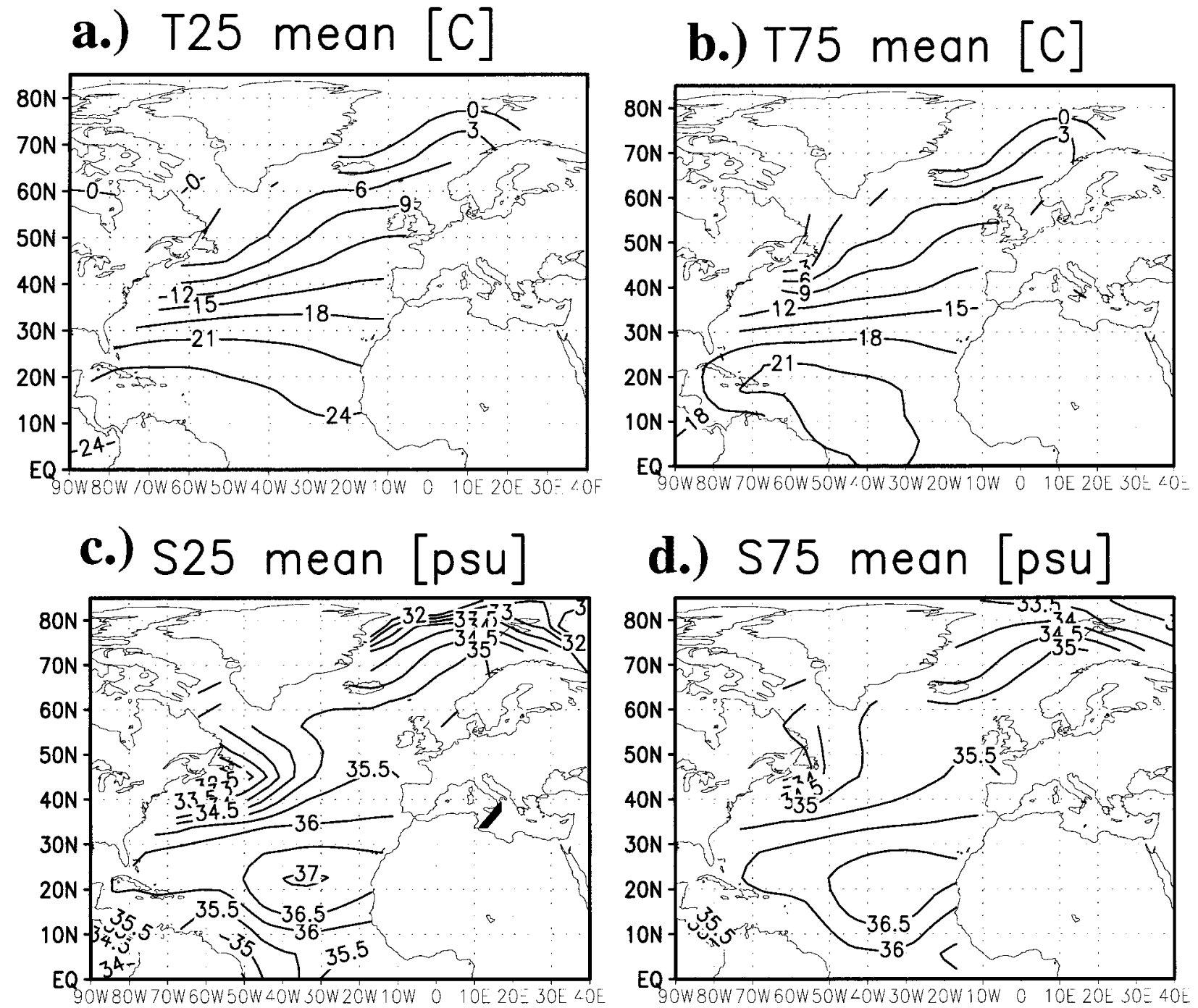

Fig. 1. Mean fields of the temperatures at 25-m and 75-m depth $\left({ }^{\circ} \mathrm{C}\right)$ (upper panels) and salinities (psu) (lower panels) averaged over all 700 model yr.

some climate drift problems, although encouraging progress has been made quite recently.

\section{Interdecadal timescales}

The search for climate modes with a distinct period that can be explained by a consistent physical mechanism is a major goal of climate research. Spectral methods help as a mathematical tool to infer characteristic periods.

Figure 6 shows the temporal evolution of the maximum of the meridional overturning in the Atlantic after subtracting the trend. The same index was also used by Delworth et al. (1993). Note that the THC index has a trend of approximately $0.005 \mathrm{~Sv} 100 \mathrm{a}^{-1}\left(\mathrm{~Sv} \equiv 10^{6} \mathrm{~m}^{3}\right.$ $\left.\mathrm{s}^{-1}\right)$. Also shown is a low-pass filtered (5-yr running mean) version of the time series to highlight the lowfrequency variability. The model simulates interdecadal fluctuations of approximately $10 \%(\sim 2-3 \mathrm{~Sv})$ of the mean transport, which might have important consequences for the climate in the North Atlantic region. Thus, Fig. 6 is used in the subsequent analyses as a reference time series.

Figure 7 shows a Fourier spectrum of the maximum of the meridional model overturning in the Atlantic. The spectrum was obtained using a Bartlett window and 15 degrees of freedom. It is tested against the hypothesis that the signal is generated by a first-order autoregressive process (yielding a red noise spectrum), and the 95\% confidence limit for the rejection of the red noise hypothesis is also displayed. The appropriate spectrum of the red noise process was obtained by calculating the first-order maximum entropy spectrum of the THC index. The THC index shows enhanced spectral density at a frequency of about 0.03 cycle per year (period of about 35 years) and at about 0.008 cycle per year (period 


\section{Pot. Energy Loss by Convection $\mathrm{W} / \mathrm{m}^{\wedge} 2$}

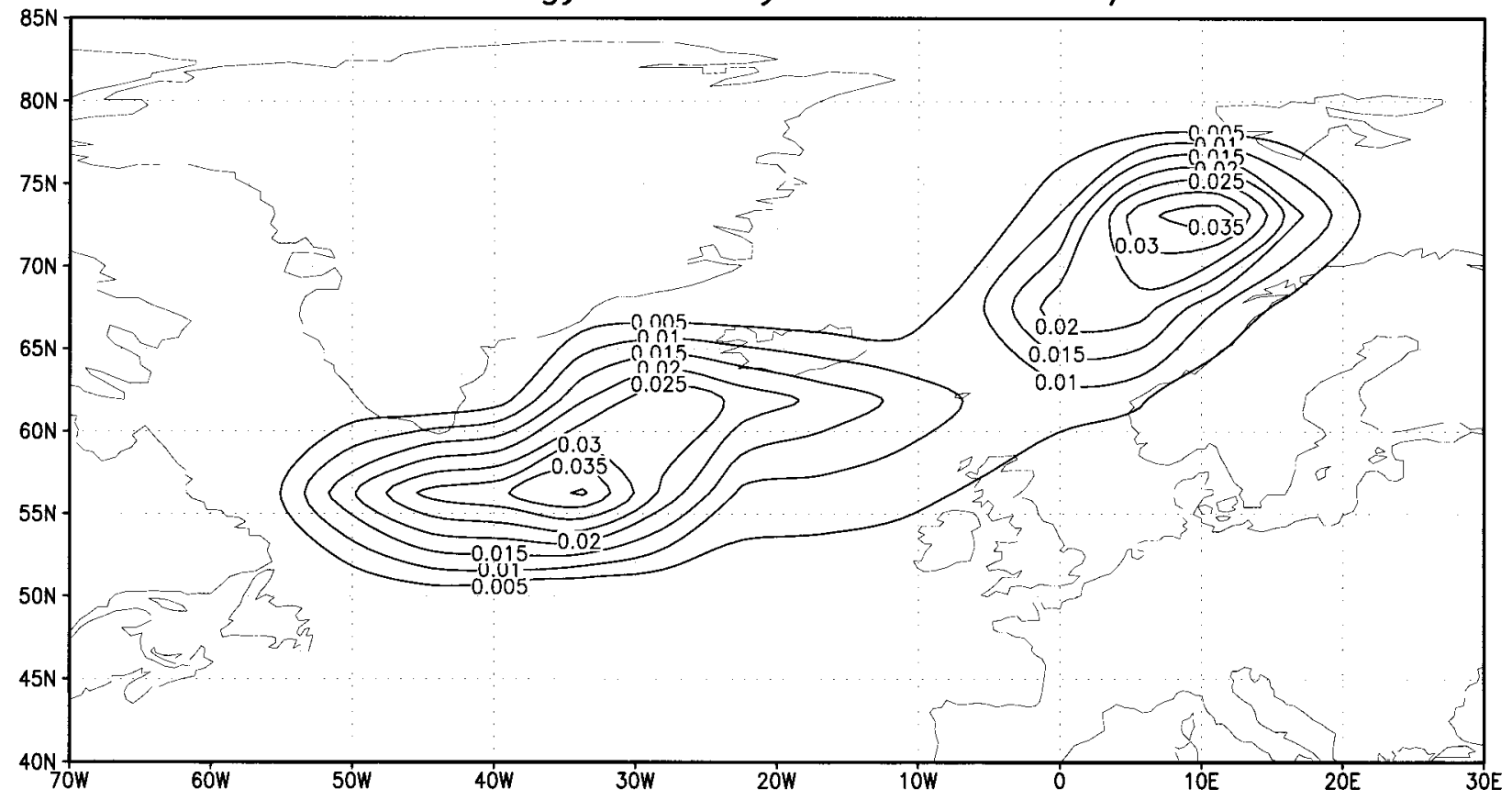

FIG. 2. Regions of mean potential energy loss by convection $\left(\mathrm{W} \mathrm{m}^{-2}\right)$ in the North Atlantic averaged over all $700 \mathrm{model}$ yr.

of 125 years). Both peaks leave the $95 \%$ confidence level of the first-order autoregressive process, indicating that other processes than just the integration of synoptic weather noise [in the sense of the stochastic climate model of Hasselmann (1976)] are involved. The THC spectrum is robust against reasonable changes of the window width. The spectral characteristics of the over- turning time series are neither consistent with a firstnor a second-order autoregressive process. The sharp drop of the spectrum at periods around 10-15 years implies that the THC has the properties of a low-pass filter. This feature is different from the findings of Griffies and Tziperman (1995), who argue that the THC in the Geophysical Fluid Dynamics Laboratory (GFDL)

vert. int. barotrop. streamfunction [Sv]

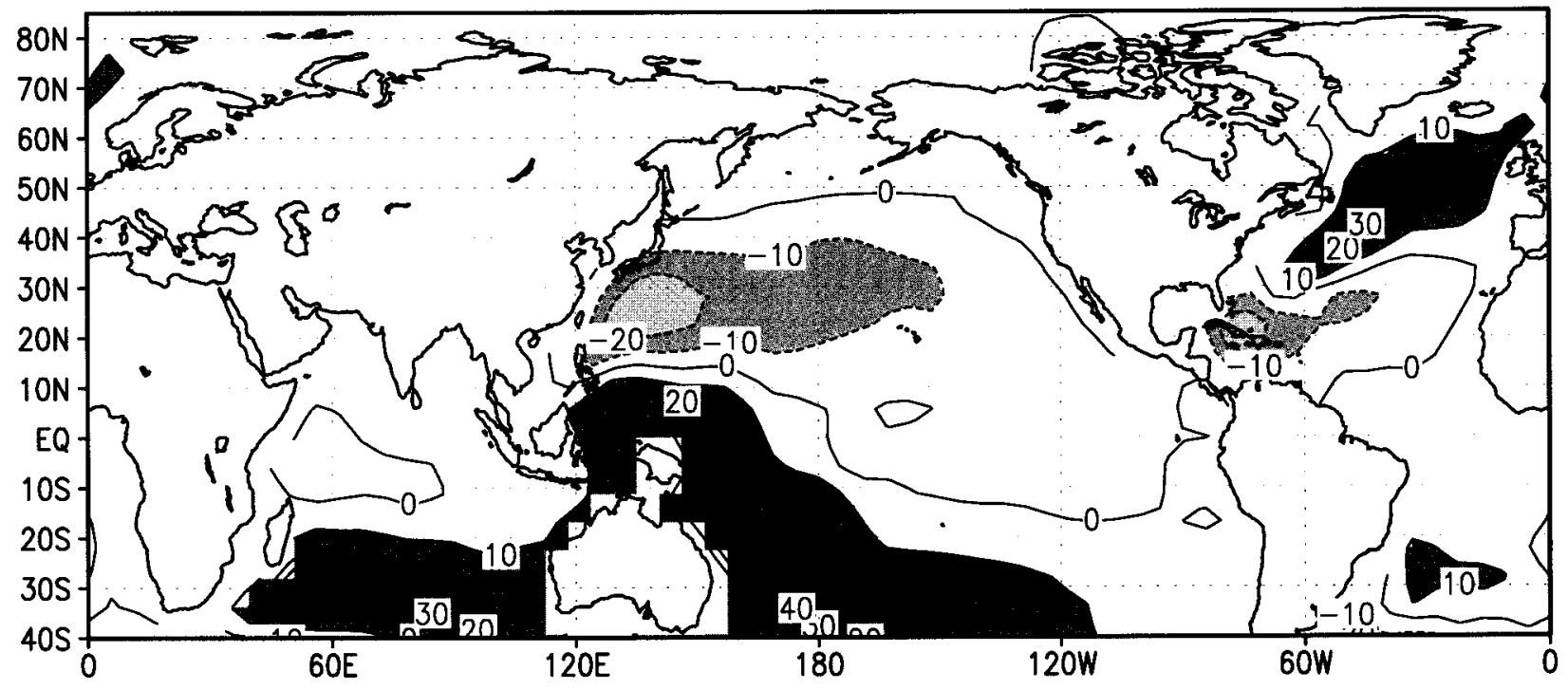

FIG. 3. Barotropic streamfunction (Sv) averaged over all 700 model yr. Negative values denote clockwise circulation. 

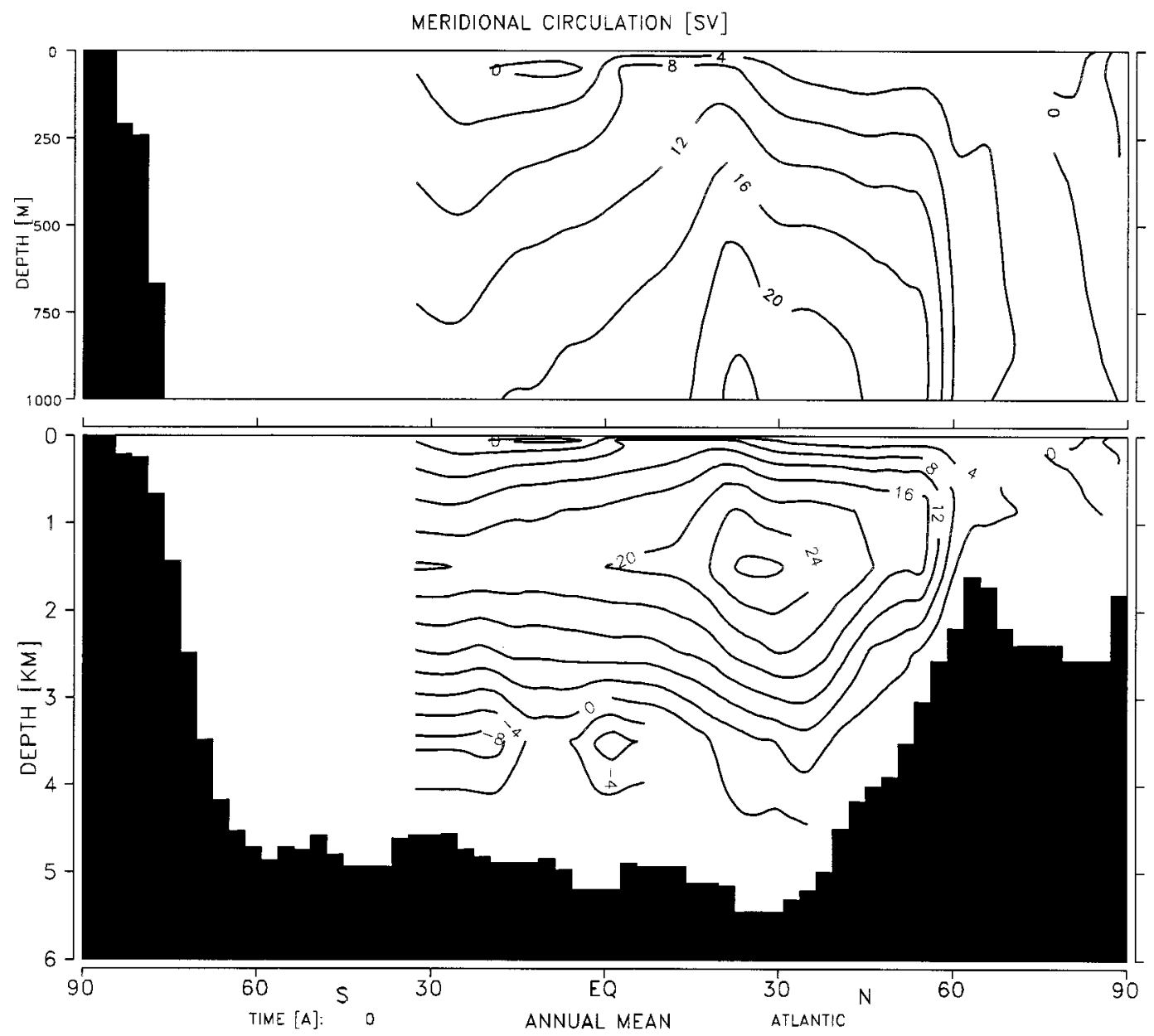

FIG. 4. Zonally integrated streamfunction (Sv) of the Atlantic as a function of depth and latitude averaged over all 700 model yr.

a.) (GISST-trend)

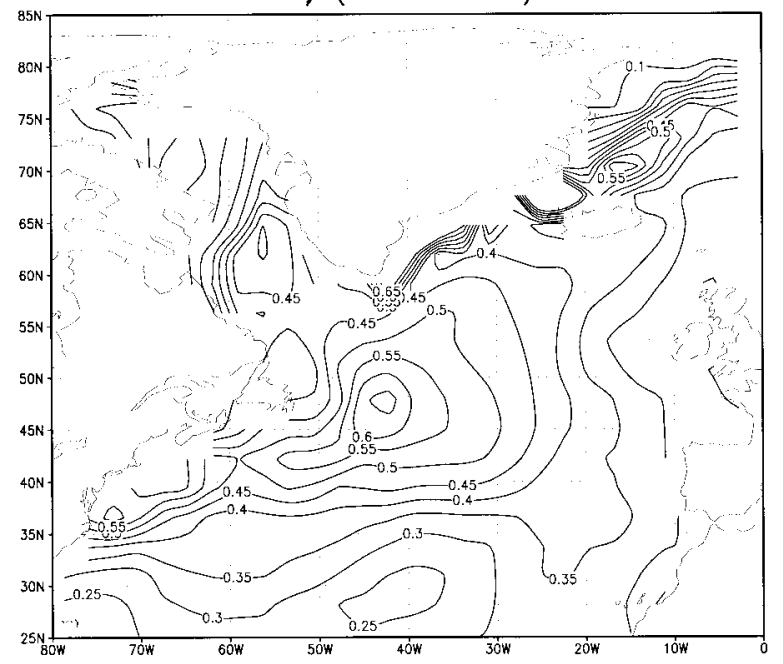

b.) STDV (E3/LSG-trend)

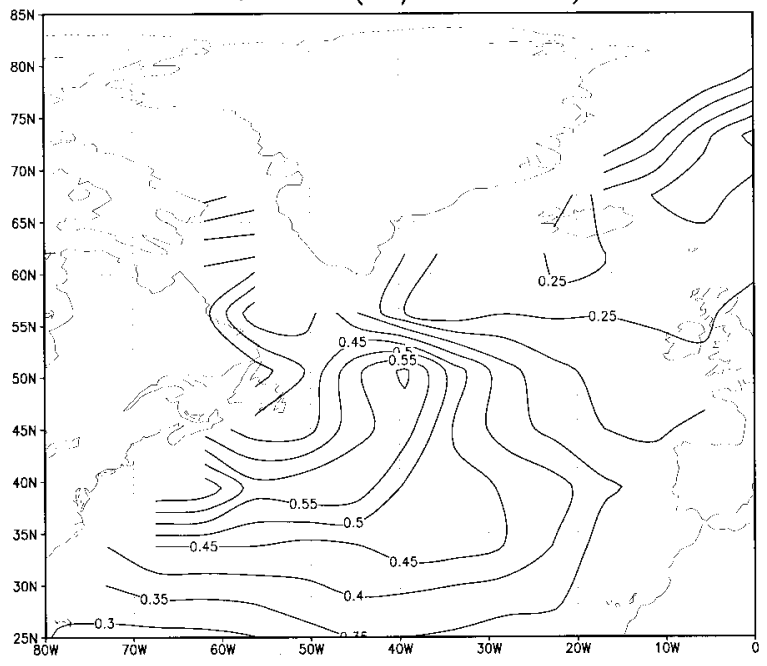

FIG. 5. (a) Standard deviation of the observed annual SSTA fields for 1903-94. A least squares fit was applied to remove the trend in the data. (b) Same as in (a) but for the SSTA of the 700-yr model integration. 


\section{Max. meridional overturning}

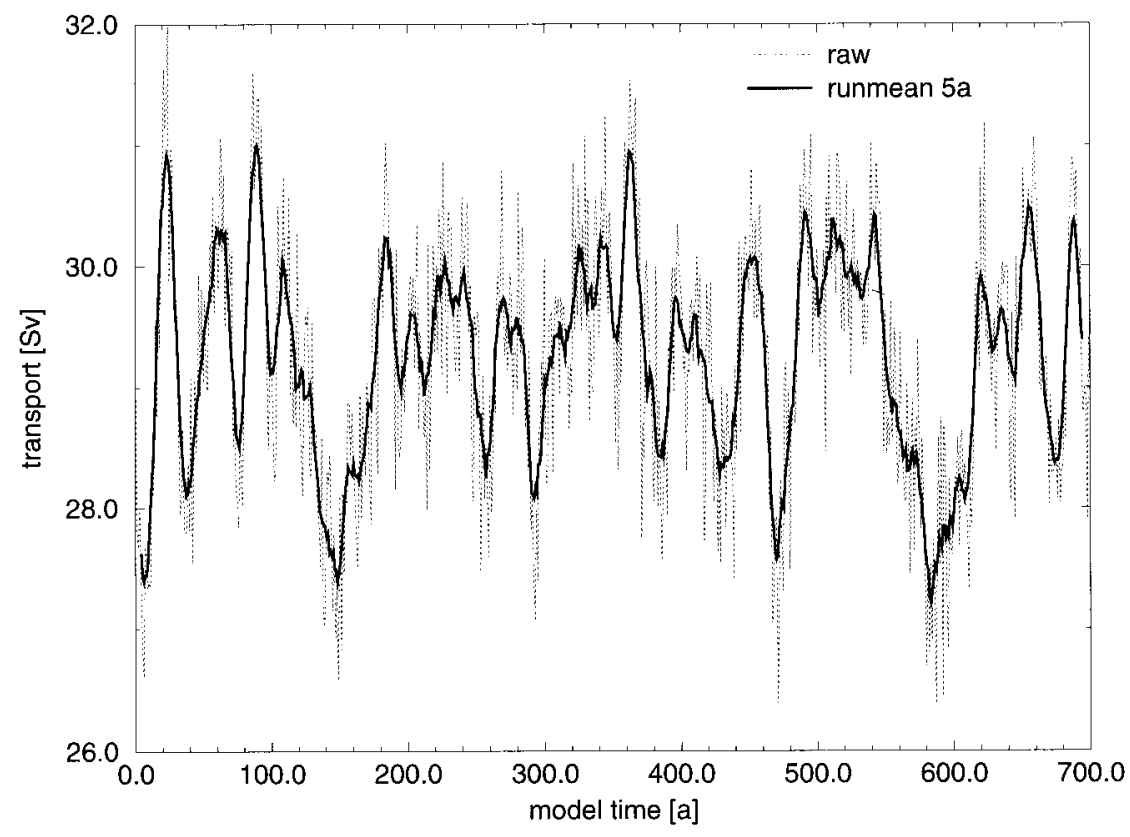

FIG. 6. Detrended time series of the maximum of the Atlantic meridional overturning (Sv).

CGCM can be understood as a noise-driven oscillator. Our goal is to understand which climate processes are participating in the generation of interdecadal Northern Hemispheric climate variability associated with the 35yr period. An index of the Labrador Sea sea-ice volume and the THC index do not show any coherence on interdecadal timescales (not shown here). Thus, we conclude that sea-ice effects do not play an important role

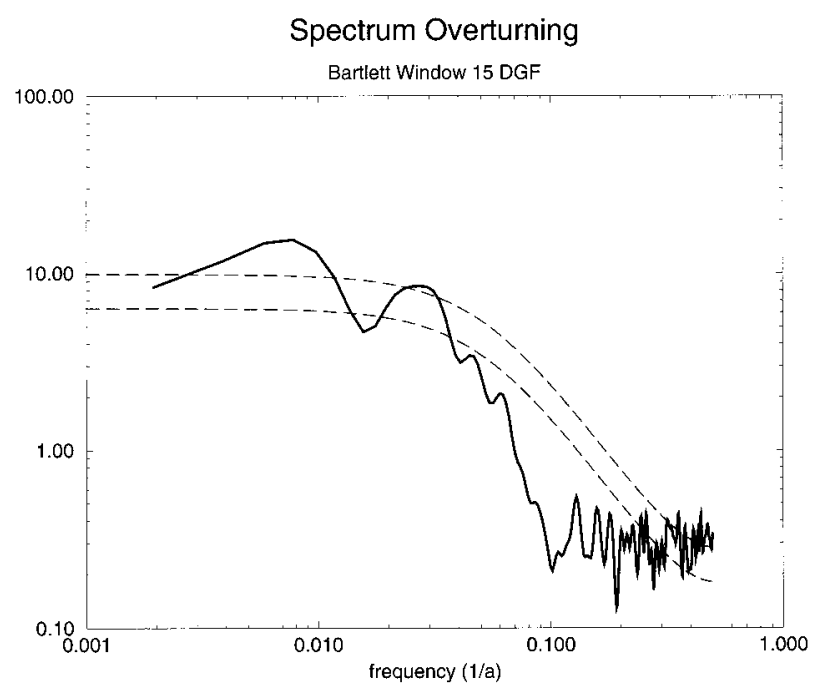

FIG. 7. Power spectrum $\left(\mathrm{Sv}^{2} \mathrm{a}\right)$ of the meridional overturning index calculated using a Bartlett window and 15 degrees of freedom. The power spectrum of a fitted AR(1) process and its $95 \%$ confidence limit are displayed by the dashed lines. in the 35-yr mode. Figure 8a displays a spectrum of a North Atlantic SST anomaly (SSTA) index. The averaging region $\left(70^{\circ}-20^{\circ} \mathrm{W}, 30^{\circ}-50^{\circ} \mathrm{N}\right)$ represents the area where maximum variance is explained by the interdecadal mode. The spectrum was calculated using normalized annual data and a Bartlett window with a width of 140 years (15 degrees of freedom). It shows a significant peak at about 0.03 cycle per year (period of $\sim 35$ years). Thus, interdecadal fluctuations in the THC are related to North Atlantic SST anomalies. This relationship is also underscored by the high coherence (not shown) between the SSTA in this region and the overturning index, which exceeds the $95 \%$ limit at this frequency. The decadal peak in Fig. 8a with a period of about 15 years (frequency $\sim 0.07$ cycle per year) is associated with variability within the subtropical gyre similar to that described in the study of Grötzner et al. (1998). However, it does not exceed the $95 \%$ confidence limit of a first-order autoregressive process. This 15-yr mode is highly coherent with the decadal (15 years) variability found in the simulated North Atlantic seaice volume and the pressure in the Icelandic low. These findings are consistent with the observational study of Deser and Blackmon (1993) and will be investigated in a forthcoming paper.

Figure $8 \mathrm{~b}$ shows the spectrum of a North Pacific SSTA index $\left(120^{\circ} \mathrm{E}-160^{\circ} \mathrm{W}, 20^{\circ}-40^{\circ} \mathrm{N}\right)$. The spectrum was calculated in the same way as the spectrum of the Atlantic SST index. The significant 35-yr peak found in the North Atlantic can also be seen in the North Pacific SSTA spectrum. Thus, the North Atlantic and 
a.)

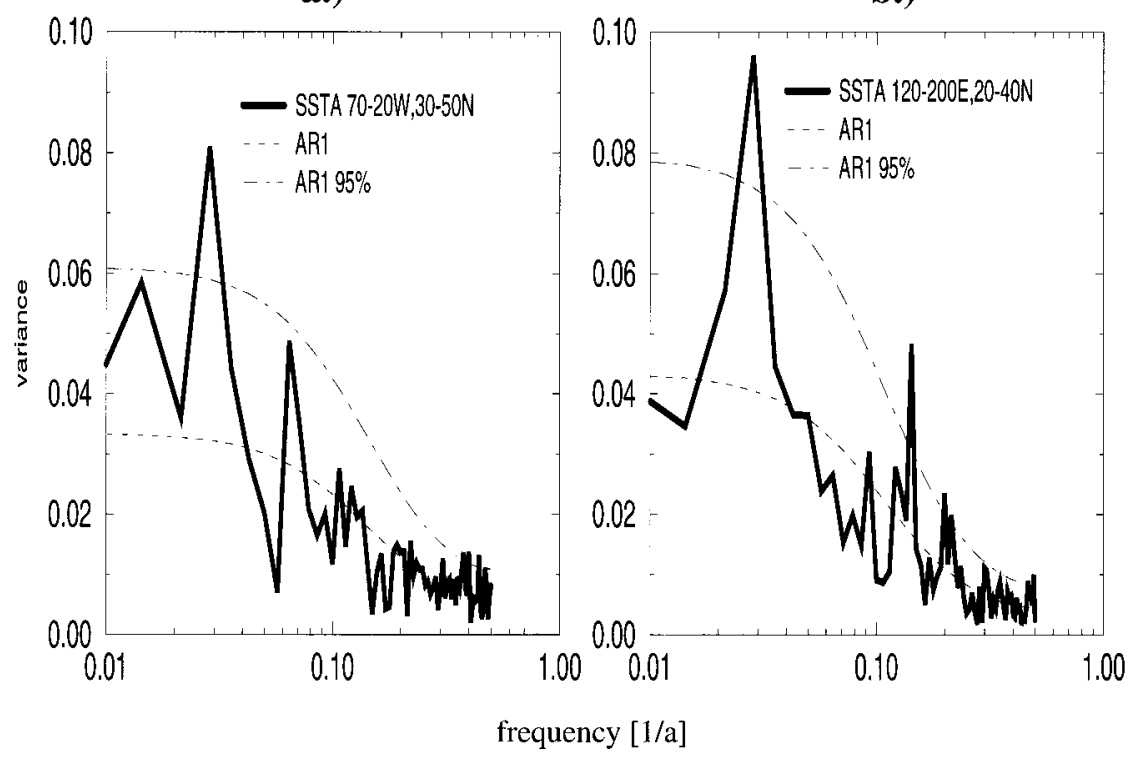

FIG. 8. (a) Power spectrum of the detrended and normalized SST anomalies averaged over the North Atlantic index region $30^{\circ}-50^{\circ} \mathrm{N}, 70^{\circ}-20^{\circ} \mathrm{W}$. The spectrum was obtained by using annual data and a Bartlett window with 15 degrees of freedom. It is tested against a first-order autoregressive process (dashed line). The 95\% confidence limit is represented by the dashed-dotted line. (b) Same as in (a) but for the North Pacific index region $120^{\circ} \mathrm{E}-160^{\circ} \mathrm{W}, 20^{\circ}-40^{\circ} \mathrm{N}$.

the North Pacific Oceans seem to be coupled on interdecadal timescales. Since both ocean basins have different geometries and therefore timescales, we believe that the most reasonable explanation for the panoceanic connection is an atmospheric coupling of the two oceans.

The atmospheric coupling of the two oceans is confirmed by an EOF expansion of the Northern Hemispheric $\left(20^{\circ}-85^{\circ} \mathrm{N}\right) 500-\mathrm{hPa}$ geopotential height anomalies. The leading EOF, which explains $26 \%$ of the total variance is shown in Fig. 9a. The dominant pattern shows that the weakened subtropical anticyclones go along with a weakened Icelandic low. The pattern in the Atlantic region is the North Atlantic Oscillation (NAO). The spectrum of the corresponding first principal component (Fig. 9b) shows a clear interdecadal peak at a period near 30-35 years.

To verify that Atlantic and Pacific SST anomalies oscillate synchronously with a period of 35 years, a cross-spectral analysis was performed between the two SSTA indices shown in Figs. $8 \mathrm{a}$ and $8 \mathrm{~b}$. The corresponding phase and the squared coherence spectra are displayed in Figs. 10a and 10b, respectively. For frequencies of about 0.03 cycle per year ( $35 \mathrm{yr}$ period) the Pacific and the Atlantic vary in phase. The atmosphere can provide only an instantanous coupling mechanism between the two oceans. The squared coherence for the 35 -year period reaches the $99 \%$ level, as can be inferred from Fig. 10b. It is unlikely that this kind of temperature synchronization is due to pure ocean processes because timescales (either associated with wave or advective processes) are of the order of many years. The decadal and interdecadal peaks discussed in this section are very stable features, which show up also by applying other spectral methods, such as wavelet and maximum entropy techniques.

Thus, we have identified a Northern Hemispheric interdecadal climate mode with a period of 35 years. Figure 11 summarizes the different hypotheses that were proposed to explain the interdecadal variability in the Northern Hemisphere. Delworth et al. (1993) analyzing a multicentury integration with the GFDL CGCM argue that atmospheric forcing as well as the atmospheric response to SST anomalies are of minor importance ( $\mathrm{T}$. L. Delworth 1996, personal communication). They explain the interdecadal variability in the North Atlantic mainly in terms of ocean dynamics. From this viewpoint no synchronous panoceanic connections can arise. Analyzing also the GFDL CGCM, Griffies and Tziperman (1995) investigate the role of atmospheric noise for the generation of the Delworth mode. They argue that the THC variability may be understood within the framework of a noise-driven linear oscillator. In contrast, our findings, in particular the panoceanic connection and the existence of an atmospheric peak at 30-35 years, imply the existence of a coupled atmosphere-ocean mode. However, note that the hypothesis of James and James (1989), who identify long-term internal variability in a simple atmospheric model, could explain our findings also. The James and James hypothesis cannot be simply rejected by our findings. Only atmospheric or coupled atmosphere-mixed layer experiments can 


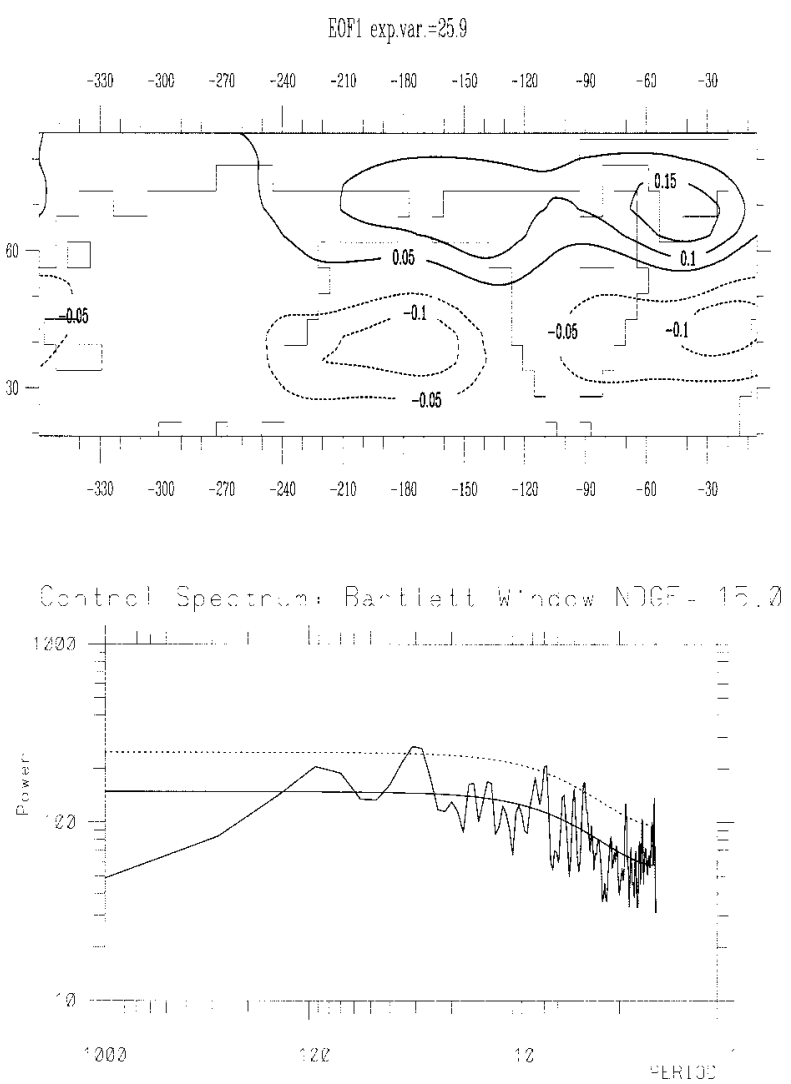

FIG. 9. (a) 1.EOF of annual Northern Hemispheric 500-hPa height anomalies. (b) Power spectrum of the corresponding first principal component. The $x$ axis denotes the period in years. The spectrum was obtained using a Bartlett window and 15 degress of freedom and is tested against a red noise spectrum. The $95 \%$ confidence limit is represented by the dotted line.

clarify whether the atmosphere is able to generate interdecadal eigenmodes.

\section{Physics of the North Atlantic interdecadal mode}

We have shown that the meridional overturning exhibits a characteristic oscillatory behavior on timescales of about 35 years. To study how the ocean and the atmosphere interact on this timescale, we analyze several oceanic and atmospheric variables in relation to the meridional overturning strength.

\section{a. Atlantic air-sea interactions}

For the following discussion, lag regression plots between the bandpass-filtered THC index and annually averaged atmospheric and oceanic fields are calculated. The THC index was bandpass filtered, retaining variability with periods between 25 and 45 years. The filtering window is buffered at both ends by cosine tails in order to suppress secondary maxima that might occur for a pure rectangular filter. Figures $12-15$ show the conditions at lags -10 (10 years prior to the maximum
Phase, Coherence squared SSTA (120-200E,20-40N/290-340W,30-50N)
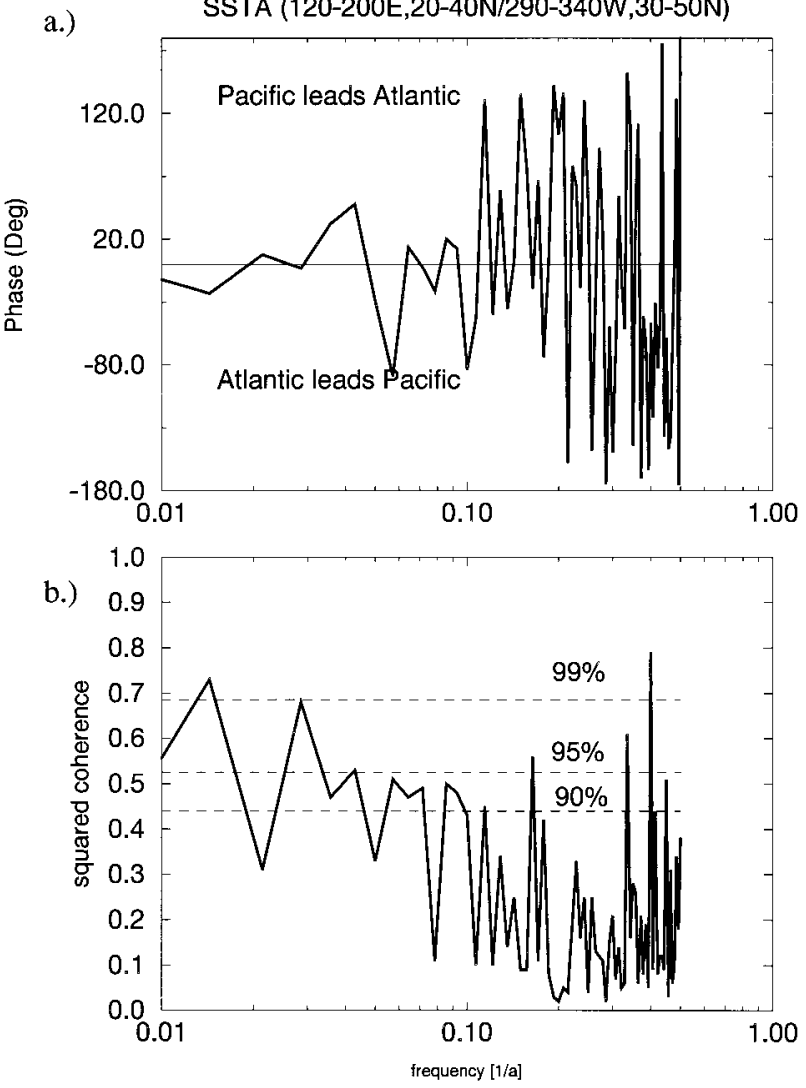

FIG. 10. (a) Phase spectrum between the normalized and detrended SSTA indexes shown in Figs. 8a and 8b. The Bartlett procedure was applied with a chunk width of 140 yr. (b) Squared coherence spectrum of the Pacific and Atlantic indexes. The 90\%, 95\%, and 99\% confidence limits for nonzero coherence are displayed as dashed lines.

overturning), lag -5 , lag 0 , and lag +5 for SLP, SST, surface freshwater flux (including also the river runoff), sea surface salinity (SSS), oceanic surface velocity, and the oceanic potential energy loss by convection. The shading indicates the regions in which the regressions exceed the $95 \%$ confidence limit of rejecting the hypothesis of zero regression.

At lag -10 (Fig. 12) anomalous conditions are characterized by a strong negative SSTA (Fig. 12b) and a weakened NAO (Fig. 12a). The negative temperature anomaly is associated with anomalous southward advection of cold subpolar waters (Fig. 12e), especially into the region off the North American coast. The meridional current anomalies in the western Atlantic north of $30^{\circ} \mathrm{N}$ are highly correlated (about -0.7 ) with the zonal wind stress anomalies (after removing high frequencies by applying an 11-yr running mean filter), which is typical for anomalous Ekman currents. A similar regression pattern of the heat flux (not shown) does not show any correspondence to the SST pattern (Fig. 12b). Hence, the surface heat flux does not contribute to the generation of midlatitudinal SST anomalies on these timescales. One should note that south 


\begin{tabular}{|l|l|l|}
\hline $\begin{array}{l}\text { paradigma for interd. } \\
\text { variability }\end{array}$ & $\begin{array}{l}\text { atmospheric \& } \\
\text { oceanic peak }\end{array}$ & panoceanic connection \\
\hline $\begin{array}{l}\text { noise dri ven ocean } \\
\text { oscillator } \\
\text { (Delworth et al.,Griffies et al.) }\end{array}$ & $\begin{array}{l}\text { no } \\
\text { atmosphheric feedback not crucial }\end{array}$ & $\begin{array}{l}\text { no } \\
\text { different timescales of Pacific and } \\
\text { Atlantic }\end{array}$ \\
\hline $\begin{array}{l}\text { coupled mode } \\
\text { (this study) }\end{array}$ & $\begin{array}{l}\text { y es } \\
\text { memory resides in the ocean }\end{array}$ & $\begin{array}{l}\text { y es } \\
\text { atmosphere is the coupling device }\end{array}$ \\
\hline $\begin{array}{l}\text { atmospheric mode } \\
\text { (James and James) }\end{array}$ & $\begin{array}{l}\text { y es } \\
\text { internal atmospheric memory }\end{array}$ & $\begin{array}{l}\text { yes } \\
\text { forcing oceans with one frequency }\end{array}$ \\
\hline
\end{tabular}

FIG. 11. Table of different hypotheses that can explain interdecadal variability.

of $45^{\circ} \mathrm{N}$ the anomalous Ekman currents support further cooling of the upper ocean, whereas north of $45^{\circ} \mathrm{N}$ they are responsible for a warming of the sea surface. The SSS anomalies (Fig. 12d) exhibit a dipolelike structure. In the region $30^{\circ}-40^{\circ} \mathrm{N}$, negative $\mathrm{SSS}$ anomalies are created mainly by an anomalously positive freshwater flux. ${ }^{2}$ This can be inferred from the close correspondence between Figs. $12 \mathrm{c}$ and $12 \mathrm{~d}$. Of particular importance are the relatively small positive SSS anomalies off Newfoundland and east of Greenland, which-after amplification-are going to play a crucial role for the phase reversal in the climate mode under consideration. The positive salinity anomalies are due to reduced freshwater supplies from the atmosphere to the ocean. A moderate increase in convection can be seen at this time (Fig. 12f), which can be attributed to positive salinity anomalies. The mechanisms that generate the subpolar SSS anomalies are discussed in more detail below. Note that the SLP (Fig. 12a) and the temperature anomaly patterns (Fig. 12b) shown here are rather similar to those shown in Bjerknes's (1964) study for the interdecadal change that was observed during 1890-1925.

The various oceanic and atmospheric anomaly fields associated with the conditions five years prior to the maximum overturning are depicted in Figs. 13a-h. The regression pattern for the anomalous SLP shows an intermediate phase of the NAO. The pressure anomalies near Iceland changed their signs (compared to lag -10 years), which is associated with an enhanced cold air advection over the northwest Atlantic. The SST anomalies in this region are positive, which leads to a strong heat loss of the ocean (not shown). The enhanced oceanic convection at lag -5 years brings warmer water masses from below to the surface, supporting further heat loss of the ocean. This is associated with a tendency to damp the SST anom-

\footnotetext{
${ }^{2}$ A negative value of the freshwater flux regressions is equivalent to a net freshwater removal from the ocean.
}

alies in the Labrador Sea. This intermediate phase of the NAO reduces further the atmospheric freshwater flux (Fig. 13c) south of Greenland, resulting in an amplification of the initial positive SSS anomaly that was first simulated at lag -10 years. The northerly winds along the west coast of Greenland have an additional effect on the surface salinities through anomalous Ekman transport (Fig. 13e) off Newfoundland (not shown). According to the mean salinity gradients (see Fig. 1), the anomalous ocean currents advect more saline waters into this region, thereby amplifying the positive salinity anomaly further. The effect of this positive salinity anomaly is a destabilization of the water column south of Greenland, leading to enhanced deep convection. At lag -5 years the strongest anomalies in the convection are simulated, indicating a lag between the convection and the maximum meridional overturning of about 5 years (Fig. 13f).

A striking resemblance between the interdecadal mode in our model and that of Delworth et al. (1993) can be found by comparing the corresponding SST, SSS, and SLP patterns. The SST and SSS composites of Delworth et al. (1993), calculated by taking SST and SSS differences between four decades with anomalously large THC index and four decades of anomalously small THC index values (shown in Figs. 6a,c of their study), have a close correspondence to the regression patterns we obtain at lag -5 years (Figs. 12b,d).

Figure 14 shows the regression patterns to the THC index for time lag 0 . The SLP pattern at lag 0 in our model (see Fig. 14a) agrees extremely well with that found in the GFDL model (see their Fig. 20), which is also true for the magnitudes. During the maximum phase of the meridional overturning, the NAO is anomalously strong, associated with anomalously strong westerlies centered near $55^{\circ} \mathrm{N}$ and anomalous easterlies at about $35^{\circ} \mathrm{N}$. The SSTA pattern is now characterized by a positive anomaly covering the whole North Atlantic. During the maximum phase of the THC, an increased northward heat transport contributes to the generation of the 
a) Regr. SLP/Overt. $\mathrm{hPa} / \mathrm{Sv}-10 \mathrm{a}$

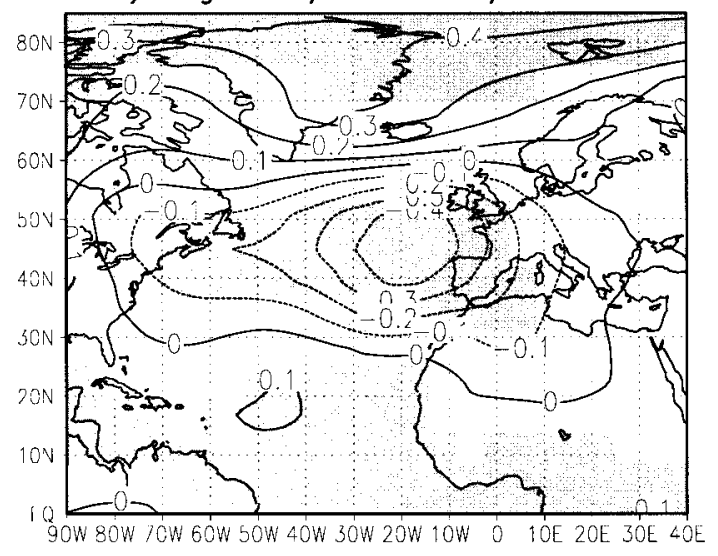

c) Regr. FWF/Overt. $\mathrm{mm} / \mathrm{d} / \mathrm{Sv}-10 \mathrm{a}$

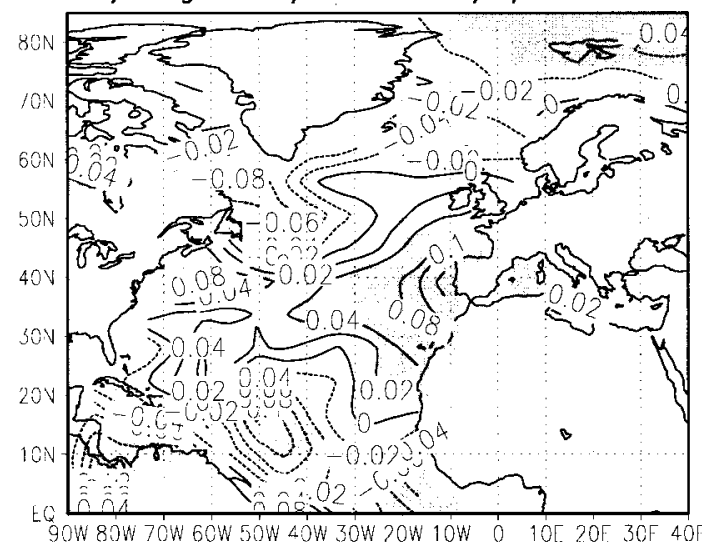

e) Regr. V25/Overt. cm/s/Sv $-10 \mathrm{a}$

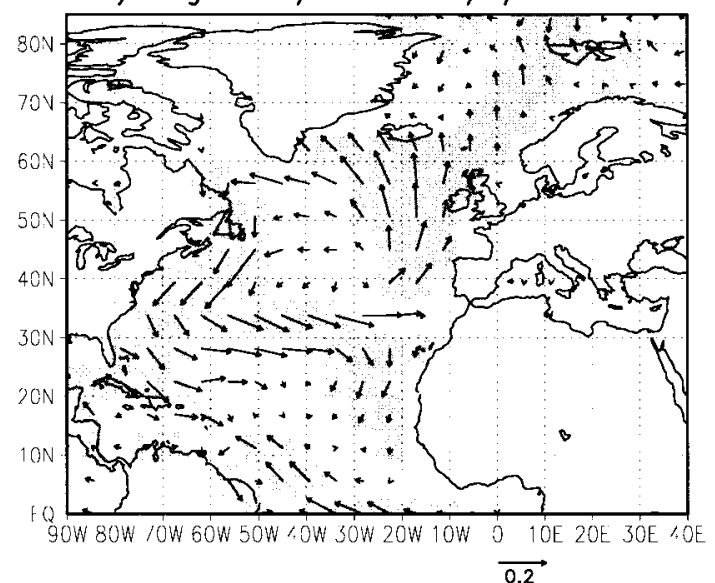

b) Regr. SST/Overt. K/Sv $-10 \mathrm{a}$

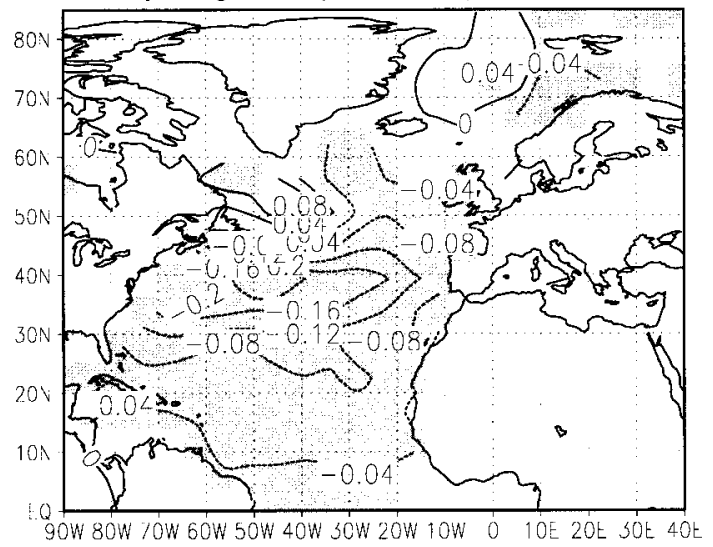

d) Regr. S25/Overt. psu/Sv $-10 a$
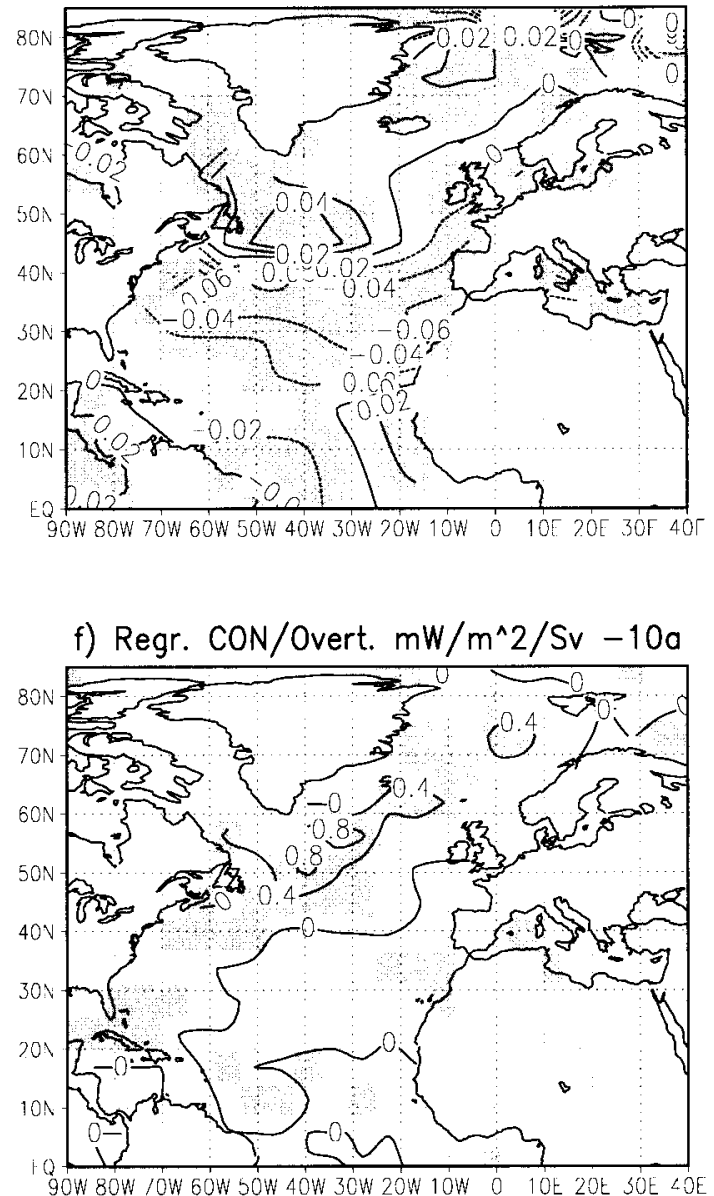

FIG. 12. Lag regressions of (a) SLP $\left(\mathrm{hPa} \mathrm{Sv}^{-1}\right)$, (b) SST $\left(\mathrm{K} \mathrm{Sv}^{-1}\right)$, (c) freshwater flux gain of the ocean (mm day $\left.{ }^{-1} \mathrm{~Sv}^{-1}\right)$, (d) $\mathrm{SSS}$ (psu $\left.\mathrm{Sv}^{-1}\right)$, (e) surface currents $\left(\mathrm{cm} \mathrm{s}^{-1} \mathrm{~Sv}^{-1}\right)$ and potential energy loss by convection $\left(\mathrm{mW} \mathrm{m}^{-2} \mathrm{~Sv}^{-1}\right)$ onto the bandpass-filtered THC index. Annual mean values were used and prior to the analysis all time series were detrended. The results are shown for a lag of $-10 \mathrm{yr}$ (i.e., 10 yr prior to the maximum overturning). 
a) Regr. SLP/Overt. $h P a / S v-5 a$

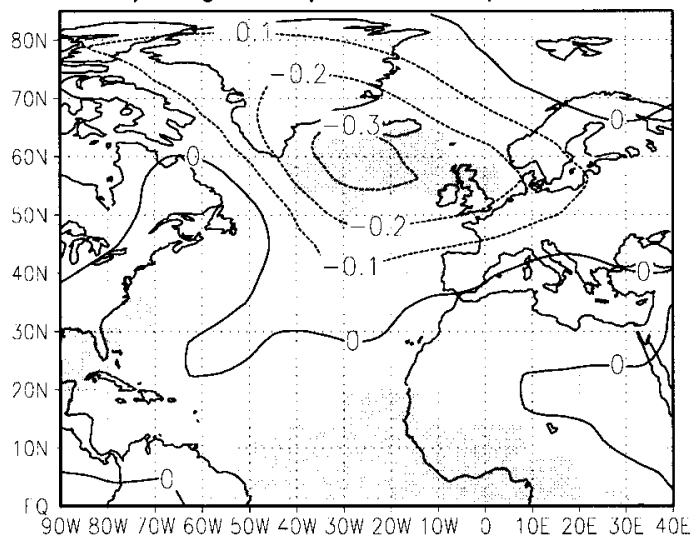

c) Regr. FWF/Overt. $\mathrm{mm} / \mathrm{d} / \mathrm{Sv}-5 \mathrm{a}$

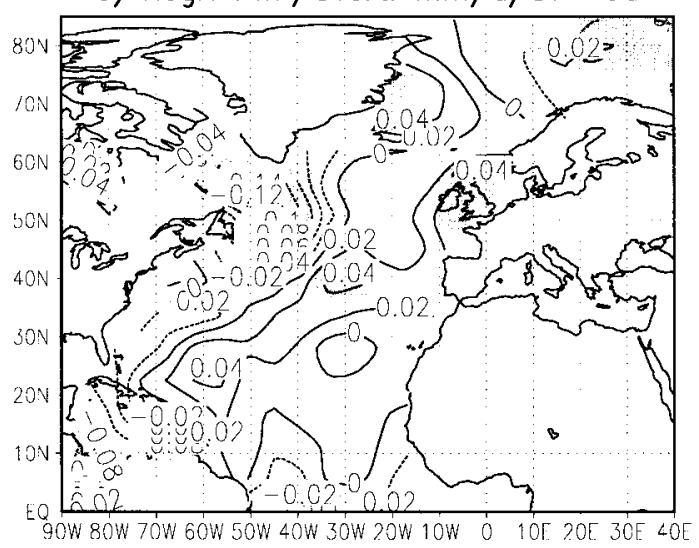

e) Regr. V25/Overt. cm $/ \mathrm{s} / \mathrm{Sv}-50$

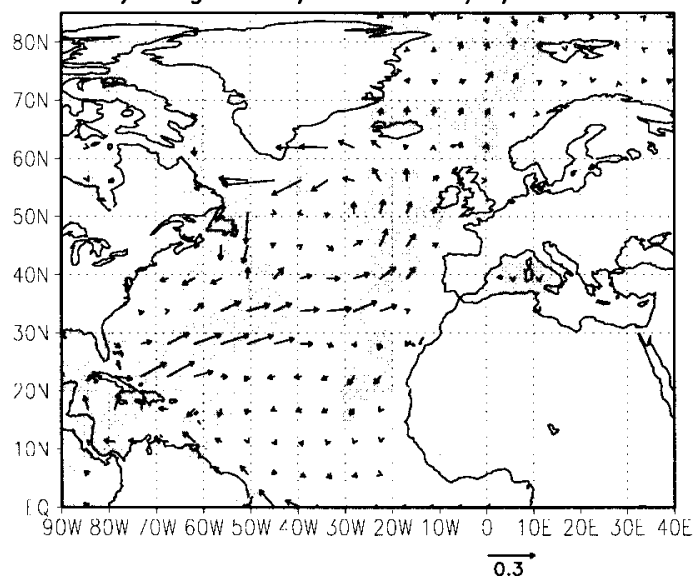

b) Regr. SST/Overt. K/Sv $-5 a$

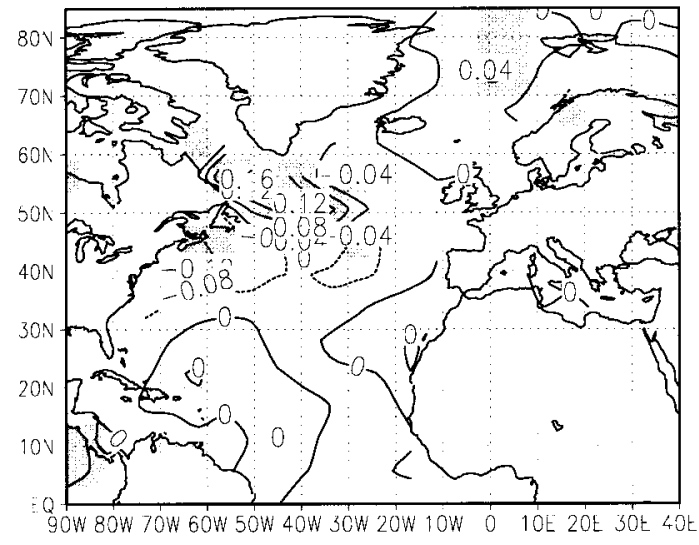

d) Regr. S25/Overt. psu/Sv $-5 a$

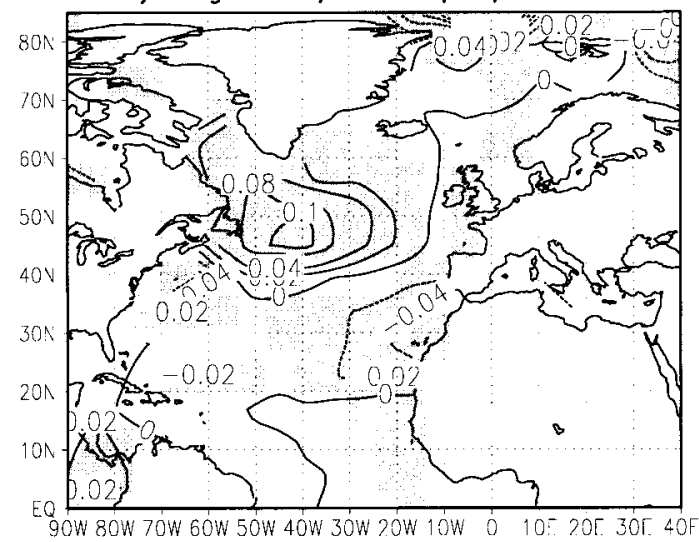

f) Regr. CON/Overt. $\mathrm{mW} / \mathrm{m}^{\wedge} 2 / \mathrm{Sv}-5 a$

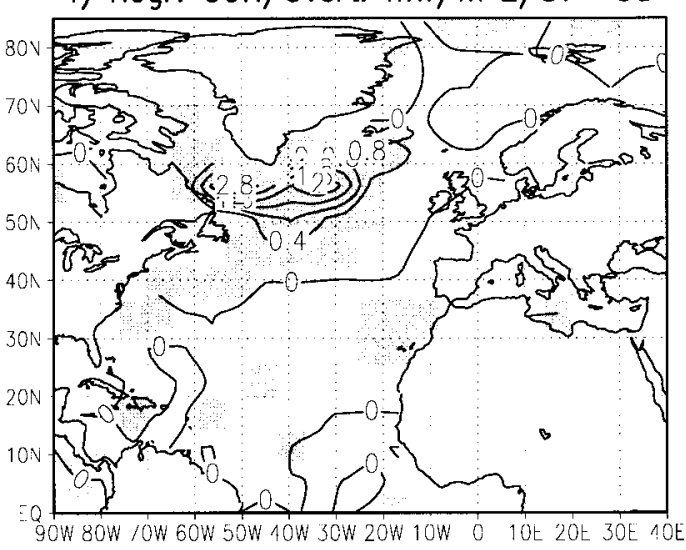

FIG. 13. Same as Fig. 12 but for lag -5 a.

positive SSTA. This SSTA seems to be amplified by the atmosphere via anomalous winds and Ekman transport. Comparing Fig. 14b to Fig. 12b we find that although the atmospheric conditions have almost changed to their reverse, there is still a positive SSTA in the Labrador
Sea, whereas south of $50^{\circ} \mathrm{N}$ the temperature pattern has changed its sign. This is a hint that the atmospheric response to SST anomalies is mainly active in the region $30^{\circ}-50^{\circ} \mathrm{N}$. The salinity anomaly (Fig. $14 \mathrm{~d}$ ) at lag 0 attains a magnitude of $0.04 \mathrm{psu} \mathrm{Sv}^{-1}$, and it has spread 
a) Regr. SLP/Overt. hPa/Sv Oa

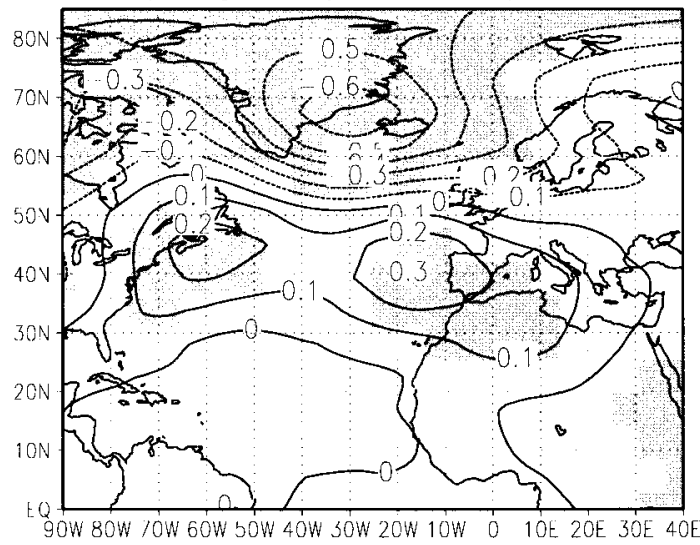

c) Regr. FWF/Overt. mm/d/Sv Oo

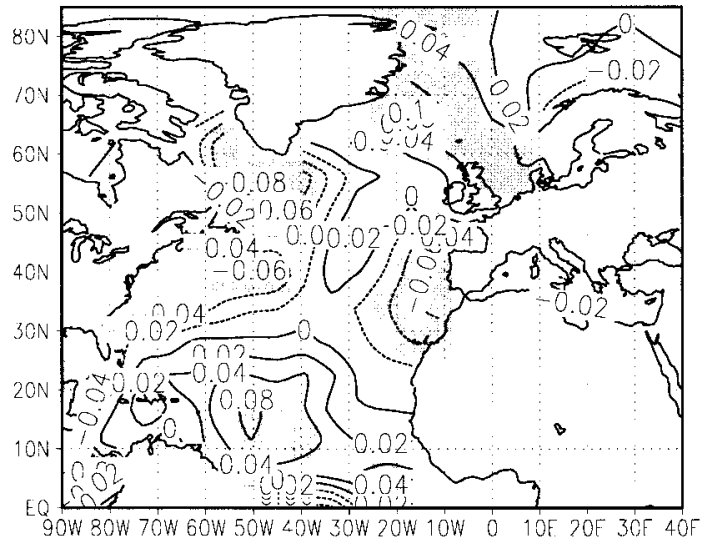

e) Regr. V25/Overt. $\mathrm{cm} / \mathrm{s} / \mathrm{Sv}$ Oa

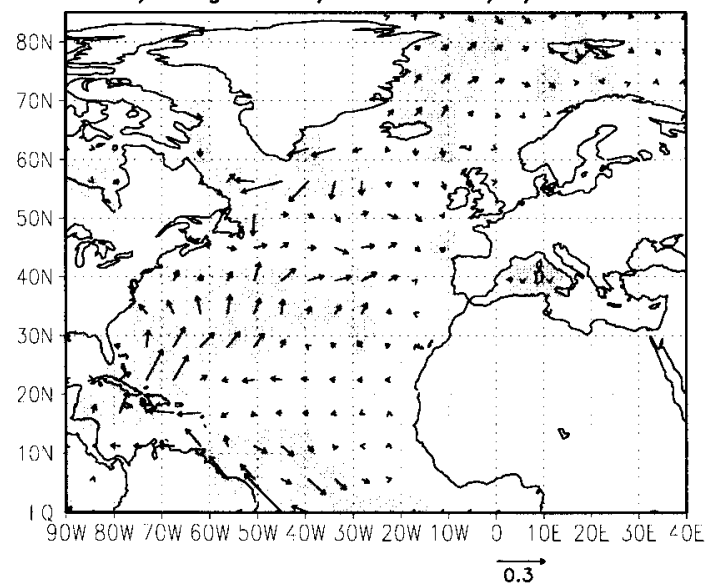

b) Regr. SST/Overt. K/Sv Oa

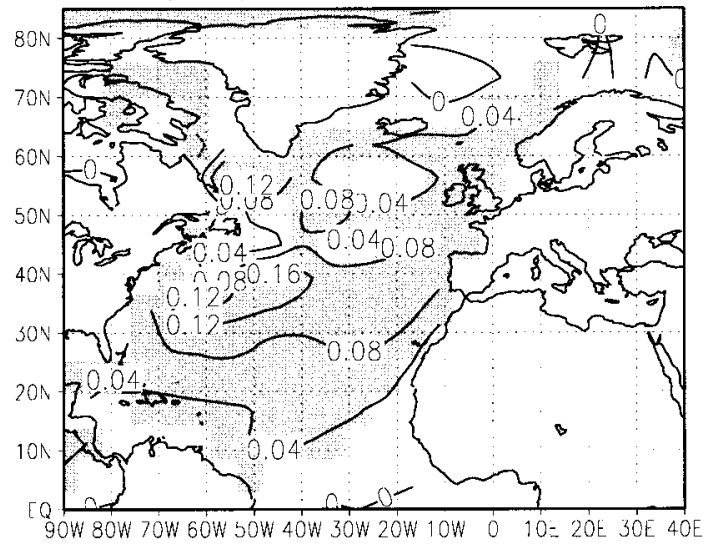

d) Regr. S25/Overt. psu/Sv Oa

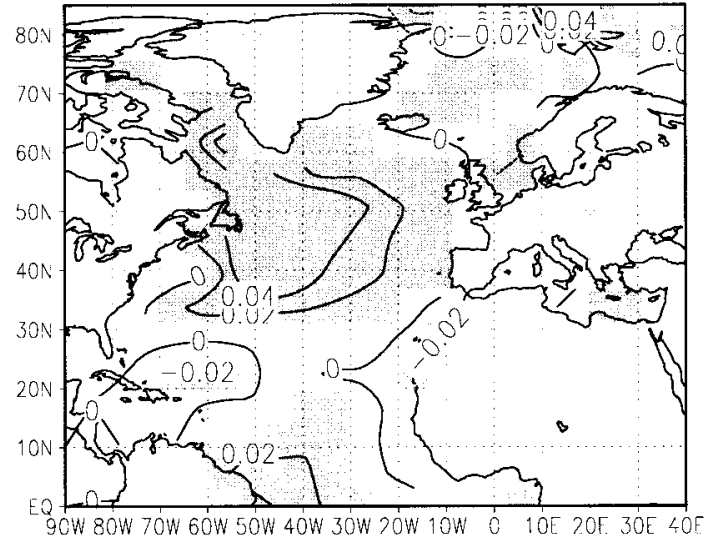

f) Regr. CON/Overt. $m W / m^{\wedge} 2 / S v O a$

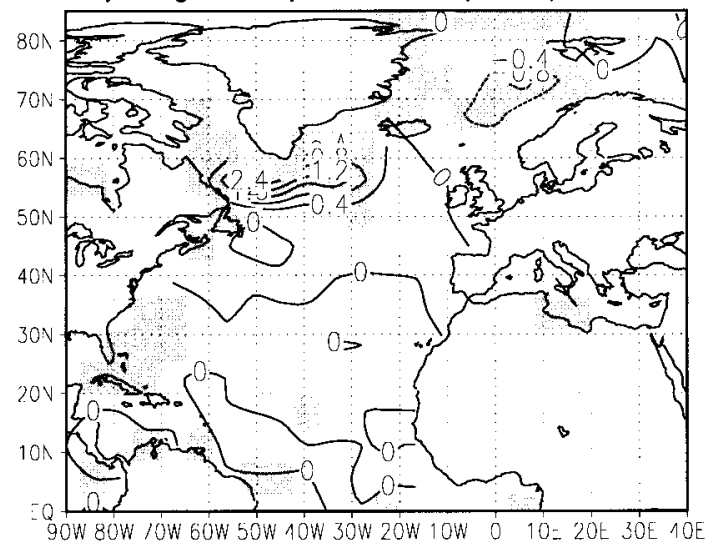

FIG. 14. Same as Fig. 12 but for lag 0 a.

relative to lag $-5 \mathrm{a}$, now covering the whole North Atlantic. The anomalous atmospheric freshwater flux (Fig. 14c) still favors the generation of positive salinity anomalies in the region $30^{\circ}-55^{\circ} \mathrm{N}$. Thus, there are several opposing mechanisms at lag 0 . There is an atmospheric tendency to amplify the salinity anomaly, and also anomalous currents south of Greenland still promote further salinity import into the northwest Atlantic. On 
the other hand, the horizontal diffusion of the salinity anomaly becomes apparent and parts of the salinity anomaly are removed from the surface by deep convection south of Greenland. This indicates that-regarding air-sea interactions-we are in an intermediate phase. Figure $14 \mathrm{~h}$ demonstrates that oceanic convection south of Greenland is still anomalously strong, while reduced convection is found in the GIN Sea (Fig. 14h). There is also evidence from observations (Dickson et al. 1996) that deep convection in the GIN Sea and the northwest Atlantic were out of phase during the postwar period. Five years after the maximum of the THC the anomalous climate conditions (Fig. 15) are basically given by the mirror images of those shown at lag -10 years, thereby completing one-half cycle.

Let us consider now the processes that are responsible for the generation of the surface salinity anomalies off Newfoundland. Figure 16 depicts a collection of lag correlations of salinity anomalies in the oceanic sinking region in the northwest Atlantic $\left(60^{\circ}-20^{\circ} \mathrm{W}, 45^{\circ}-65^{\circ} \mathrm{N}\right)$ and anomalous evaporation, sea-ice thickness, precipitation, zonal and meridional surface currents avaraged over this region, respectively. The lag correlations were obtained by removing high frequencies applying an 11yr running mean filter. Figure 16 demonstrates that the evaporation and the salinity anomalies in the sinking region vary in phase-although an in-phase relationship is expected for the time-integrated fluxes and the salinity anomaly. This feature has to be clarified. The physical time constant for the upper-ocean salinity anomalies being created by fluxes is rather short and of the order of a few months. We use in our analysis annual data and some low-pass filtering. Hence, the difference between the freshwater flux and its time integral (on the basis of short data sampling) is smeared out and we obtain an in-phase relationship between the freshwater fluxes and the salinity anomalies. The correlations indicate that SSS anomalies are forced locally in the sinking region by anomalous evaporation and anomalous zonal surface currents. As mentioned above, the latter are mainly due to anomalous wind stress over the sinking region. The roles of area-averaged sea-ice thickness and precipitation for the generation of salinity anomalies in the sinking region are negligible. It should be noted that in our model version there is no free sea-ice drift included. Instead, sea ice is created and destroyed locally by thermal processes. Thus, the direct comparison of the averaged sea-ice thickness anomalies with the salinity anomalies is justified and hence also the conclusion that sea ice does not play an important role.

To gain further insight into the generation of salinity anomalies, we investigate the vertical structure of the zonally averaged salinity anomalies in the North Atlantic. Figure 17 displays a lag regression for lag -5 between the bandpass-filtered THC index and the zonally averaged salinity anomalies as a function of depth and latitude. Lag -5 represents the conditions when maximum positive salinity anomalies can be observed in the northwest Atlantic and also when deep convection south of Greenland is at its maximum (Fig. 13). Figure 17 demonstrates that the strong positive salinity anomalies of about $0.1 \mathrm{psu} \mathrm{Sv}^{-1}$ are surface trapped, which indicates that they are generated by surface processes (such as evaporation and Ekman currents). This surfacetrapped salinity anomaly sets up the conditions (in particular a vertical density gradient) for deep convection in the sinking region. The relative roles of thermal and haline forcing for the variability of the THC shall be discussed in the next section.

\section{b. The dynamics of the THC}

Salinity is one of the key variables for long-term climate variability since it partly governs the intensity of the thermohaline overturning. It was shown in Spall (1993) that the variances of salinity anomalies are proportional to the square of the freshwater flux amplitudes in the case of small advective and diffusive timescales. The local integration of a white noise freshwater forcing in the Labrador Sea can lead to decadal low-frequency variability of the North Atlantic Ocean, as was shown in Weisse et al. (1994). ${ }^{3}$

In the previous sections we have shown that the THC is crucial in generating the interdecadal coupled climate oscillation discussed here. It was argued that the salinity anomalies are essential in destabilizing the North Atlantic Ocean. To understand whether changes in the THC are mainly triggered by thermal or haline processes, the density anomalies (obtained from the zonally averaged salinities and temperatures in the North Atlantic) are split into their thermal and haline contributions using the full nonlinear equation of state. These density contributions are set into relation to the THC again by calculating lag regressions of the field anomalies and the bandpass-filtered THC index. These regressions are then integrated over the full depth range of our ocean model and over the sinking region $45^{\circ}$ $65^{\circ} \mathrm{N}$. The result is shown in Fig. 18 . We see that salinity dominates the evolution of density anomalies in the sinking region.

However, it is the complex interplay between the thermal and the haline density parts that is responsible for the time lag of about three years between the total density and the THC index. Thus, although the temperature contribution is much smaller than the salinity contribution, the contribution of the temperature anomalies for lags -7 to +5 years is a crucial part of our $35-\mathrm{yr}$ climate mode. Regarding the role of density in the sinking region, Delworth et al. (1993) reach similar conclusions (see their Figs. 8 and 10). However, one crucial difference between our findings and those of Delworth

\footnotetext{
${ }^{3}$ In this context the mechanism of stochastic resonance (Benzi et al. 1982), which represents the constructive influence of noise in, for example, bistable systems, has to be investigated further.
} 
a) Regr. SLP/Overt. $h P a / S v 5 a$

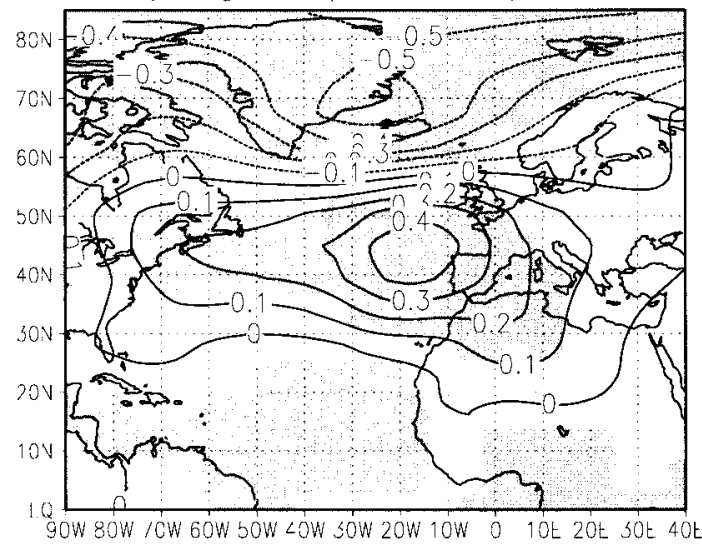

c) Regr. FWF/Overt. $\mathrm{mm} / \mathrm{d} / \mathrm{Sv} 5 \mathrm{a}$

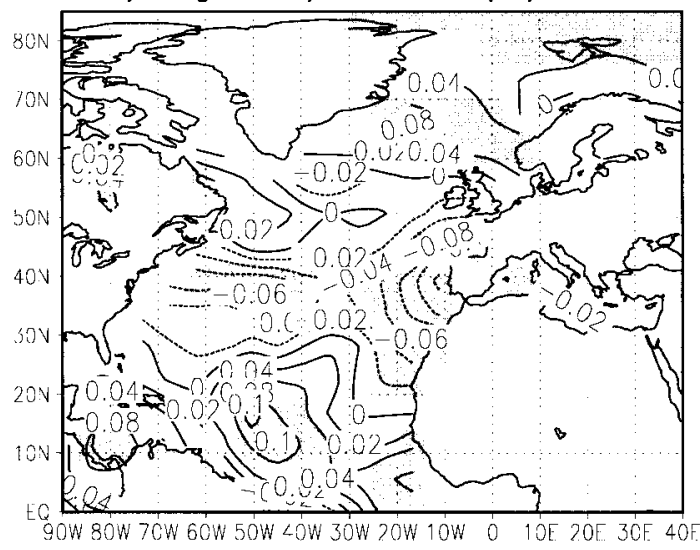

e) Regr. V25/Overt. cm/s/Sv $5 a$

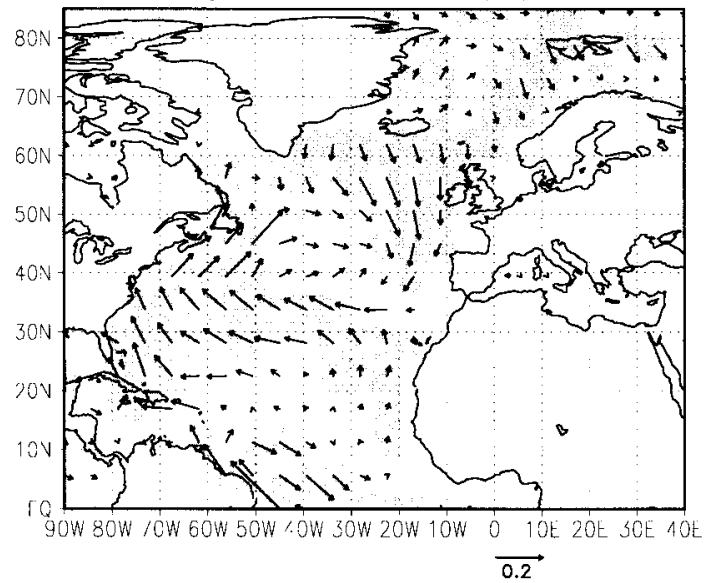

b) Regr. SST/Overt. K/Sv 5a

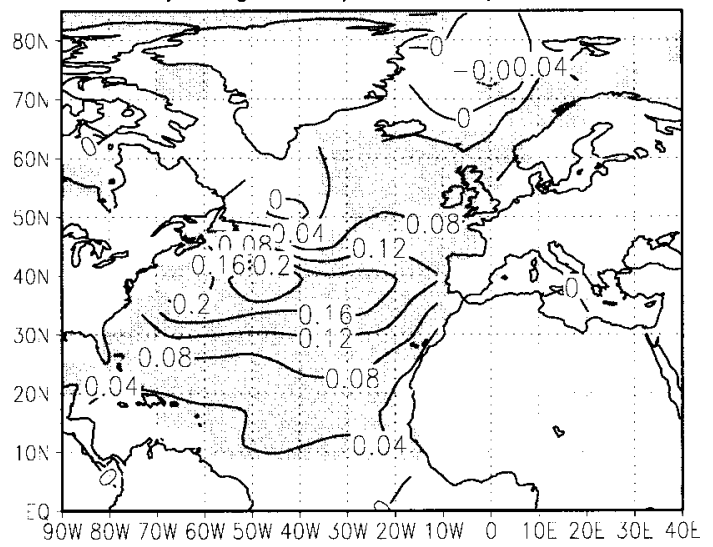

d) Regr. S25/Overt. psu/Sv 5a

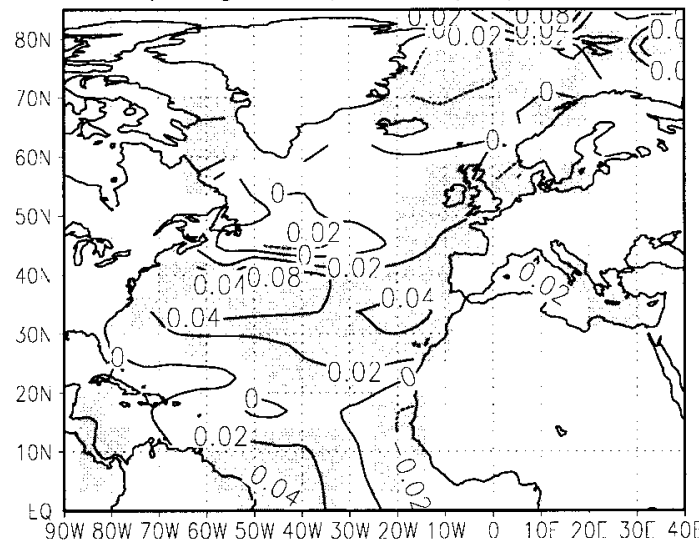

f) Regr. CON/Overt. $\mathrm{mW} / \mathrm{m}^{\wedge} 2 / \mathrm{Sv} 5 a$

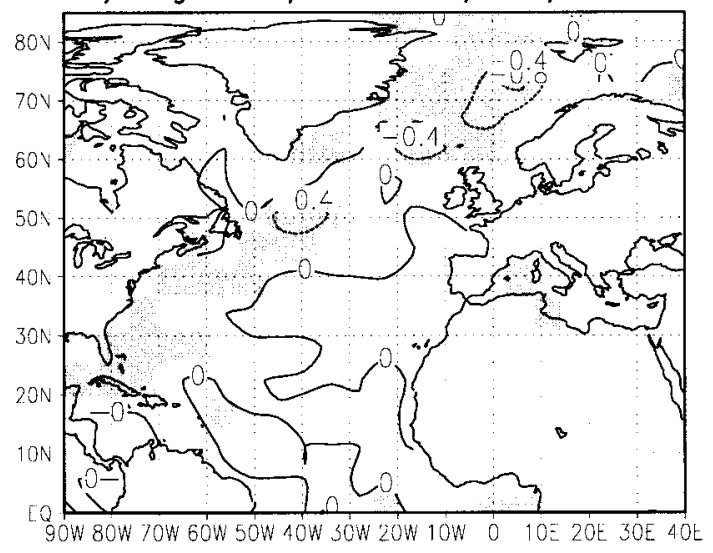

FIG. 15. Same as Fig. 12 but for lag +5 a.

et al. (1993) is that in our model the dominant haline density anomalies are created by surface processes that include strong air-sea interactions in midlatitudes.

To illustrate the vertical structure of the oscillations in the THC, lag regressions between the filtered THC index (see above) and the meridional streamfunction are calculated (Fig. 19). Positive values of the streamfunction anomalies indicate a clockwise circulation. At lag 

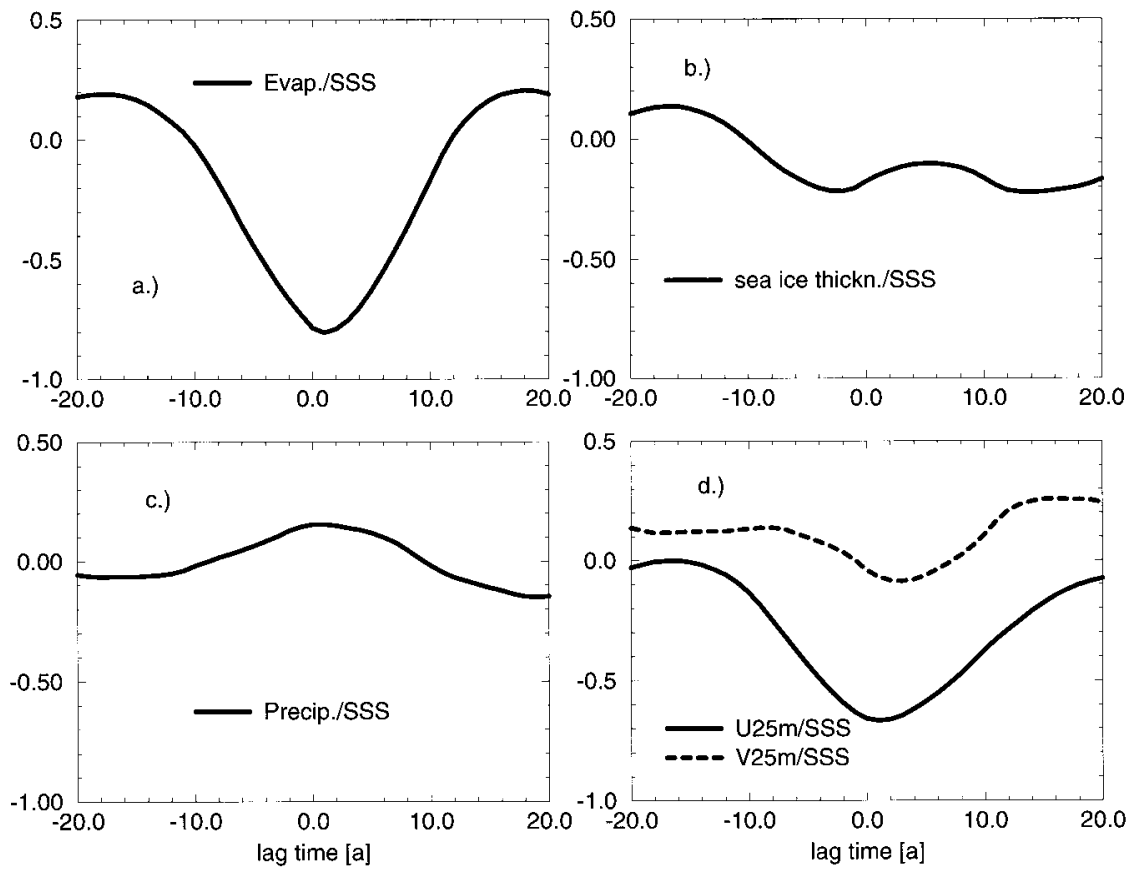

FIG. 16. Cross correlations between the SSSA averaged over the sinking region $\left(60^{\circ}-20^{\circ} \mathrm{W}\right.$, $45^{\circ}-65^{\circ} \mathrm{N}$ ) and (a) the corresponding fields of evaporation, (b) sea-ice thickness, (c) precipitation, and (d) the zonal and meridional components of the surface velocities, respectively. Positive lag times are associated with the field (evaporation, sea-ice thickness, precipitation, and surface velocities) leading the SSS anomaly.

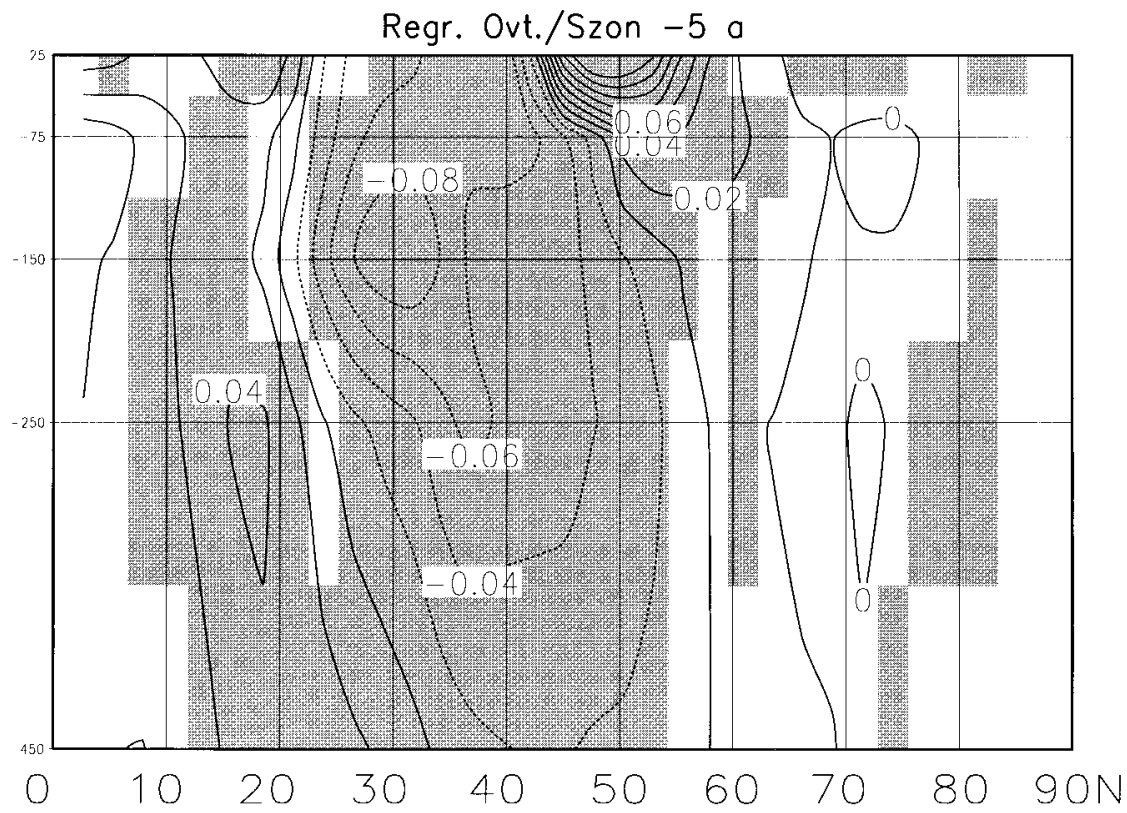

FIG. 17. Lag regression patterns between the bandpass-filtered THC index anomaly and the detrended field anomalies of the zonally averaged salinities in the North Atlantic for lag $-5 \mathrm{yr}$ as a function of depth in the upper $450 \mathrm{~m}$. Units are $\mathrm{psu} \mathrm{Sv}^{-1}$. Shading indicates nonzero regression at the $95 \%$ significance level. 


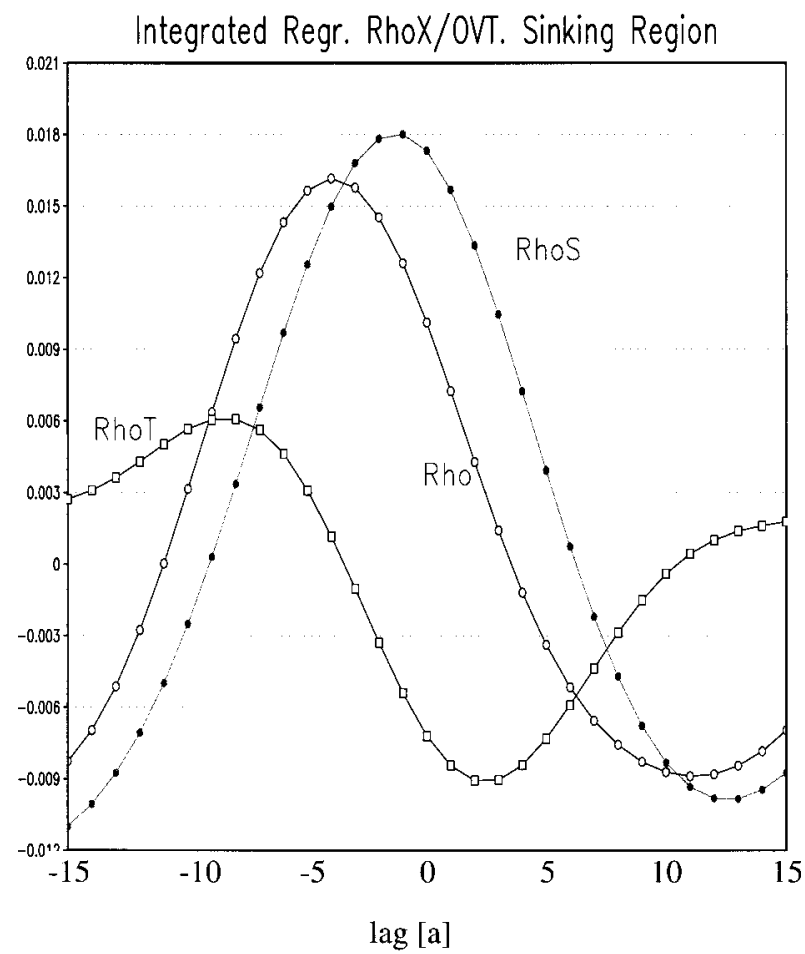

FIG. 18. Over the sinking region $\left(45^{\circ}-65^{\circ} \mathrm{N}\right)$ volume-integrated regressions of the bandpass-filtered THC index anomaly and the detrended field anomalies of the zonally averaged haline (RhoS) and thermal (RhoT) density contributions and the total (Rho) density. Units are $\mathrm{g} \mathrm{m}^{-3} \mathrm{~Sv}^{-1}$.

-10 years (Fig. 19a) the meridional overturning is in a negative phase, associated with reduced northward mass and heat transports. This is linked to a negative temperature anomaly in the North Atlantic, as shown in Fig. 12b. Five years prior to the maximum meridional overturning, a positive anomaly in the meridional circulation develops (Fig. 19b). The anomalous density conditions at lag -5 lead to the destabilization of the water column in the sinking region, thus generating enhanced overturning in the North Atlantic. As can be seen in Fig. 19c, the whole meridional overturning cell in the North Atlantic needs about five years to adjust to these new density conditions. ${ }^{4}$ This figure reveals that the new density conditions affect the Atlantic from $30^{\circ} \mathrm{S}$ to $60^{\circ} \mathrm{N}$ at all depths.

In summary, salinity anomalies are generated in the main sinking region during periods of strong oceanatmosphere coupling via anomalous freshwater fluxes

\footnotetext{
${ }^{4}$ Two processes can be responsible for the adjustment time of five years. On the one hand, the advection in the deep western boundary current can transfer the anomalous density signal southward. On the other hand, baroclinic Rossby waves and, in particular, the fast topographic Rossby waves at the western continental slope in the North Atlantic can contribute to the adjustment time of the THC to density anomalies in the sinking region.
}

and Ekman transport. The salinity anomalies grow until they alter the deep convection. Subsequently, the strength of the THC is changed in a way that reverses the SST anomaly in the North Atlantic. It is concluded that air-sea coupling and the THC act in a feedback loop to generate the interdecadal 35-yr cycle. A schematic of this feedback loop is presented in Fig. 20.

\section{Northern Hemispheric interactions}

It emerges from paleoclimate studies (Broecker et al. 1985) that strong changes in the THC may have global impacts. It is therefore tempting to study whether small changes in the THC of approximately $10 \%$ as found in our CGCM integration can also force significant climate anomalies outside the North Atlantic. To enlighten a possible coupling between the North Atlantic and North Pacific Oceans, we show lag regression plots of Northern Hemispheric upper-ocean heat content $(0-575 \mathrm{~m})$ with the bandpass-filtered THC index (Fig. 21). The heat content evolution demonstrates the existence of a common oscillatory behavior in the Atlantic and Pacific Oceans.

The patterns in the North Pacific have some resemblance to the decadal climate mode that was described in the studies of Latif and Barnett (1994, 1996) and Robertson (1996) using the ECHO1 and ECHAM1/LSG CGCMs, respectively. In their studies the hypothesis was formulated that a mode of decadal climate variability in the North Pacific (with a timescale of approximately 20 years) arises from an instability of the coupled ocean-atmosphere system. They argue that, for example, a positive SSTA in the North Pacific (the center of action in their study is located between $30^{\circ}$ and $50^{\circ} \mathrm{N}$ ) changes the meridional temperature gradient, thereby changing the baroclinity of the atmosphere. The result is a weakened Aleutian low. In their concept the atmospheric response reinforces the SSTA by anomalous heat and momentum fluxes and by anomalous Ekman transport. They argue further that the Sverdrup balance in the subtropical gyre is changed by an anomalous wind stress curl. However, the ocean adjusts with some delay, and it is this transient response that can be expressed by Rossby wave propagation that is crucial in creating the decadal oscillation.

Our model simulates at lag -10 a negative anomaly in the North Pacific, which is embraced by a positive anomaly (Fig. 21). The center of action in our model is located between $20^{\circ}$ and $40^{\circ} \mathrm{N}$ in the Pacific, whereas in the North Atlantic one finds the maximum anomalies between $30^{\circ}$ and $50^{\circ} \mathrm{N}$. The heat content signals in both oceans at lag -10 are associated with an anomalously strong (subtropical) jet stream (not shown) and anomalous low pressure systems between $30^{\circ}$ and $40^{\circ} \mathrm{N}$ in the Pacific and between $40^{\circ}$ and $60^{\circ} \mathrm{N}$ in the North Atlantic. During the intermediate phase (lag -5), the North Pacific cold anomaly weakens and the corre- 

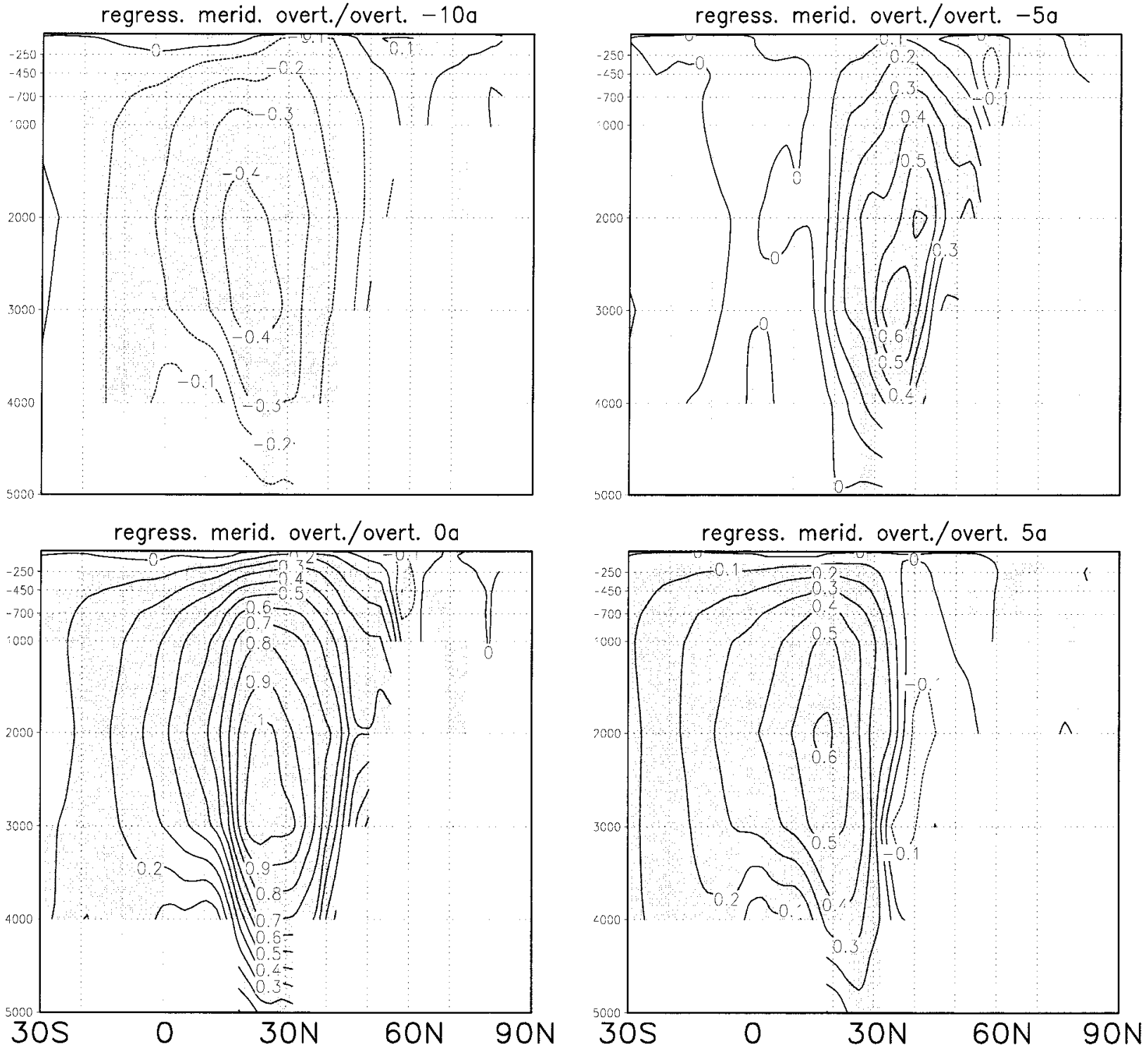

FIG. 19. Lag regression between the bandpass-filtered (transparent for periods between 25 and $45 \mathrm{yr}$ ) THC index anomaly and the meridional streamfunction anomalies for lag $-10,-5,0$, and +5 yr. Units are $\mathrm{Sv} / \mathrm{Sv}^{-1}$.

sponding upper-tropospheric wind pattern (not shown) does not reveal much organization. At lag 0 a positive heat content anomaly develops in the Pacific. Five years later $($ lag +5$)$ the model simulates basically the mirror image of the heat content anomalies at lag -10 , thereby completing one-half cycle. Without going into detail, we note that the associated Pacific SST anomalies are primarily generated by anomalous Ekman currents.

In contrast to the dynamics of the Latif and Barnett (1994, 1996) mode, which is associated with moving upper-ocean heat content anomalies due to internal ocean gyre dynamics, the Pacific heat content patterns in our CGCM exhibit a standing oscillatory behavior. This can be interpreted as an indication that the North Pacific is forced by the interdecadal mode in the North
Atlantic via atmospheric teleconnections. However, it is possible that the North Pacific SST changes feedback onto the North Atlantic through changes in the largescale atmospheric circulation. From our point of view the North Pacific gyre dynamics seem to play a minor role. At periods considerably longer than 20 years, the North Pacific Ocean is in equilibrium with the atmosphere, as was shown by experiments that were performed with the oceanic general circulation model HOPE, forced by prescribed low-frequency periodic wind stress forcing. The results of these experiments are described in Latif et al. (1996a).

To illustrate further the role of the panoceanic connections and to prove that the atmosphere is really responding to the midlatitudinal SST anomalies as hy- 


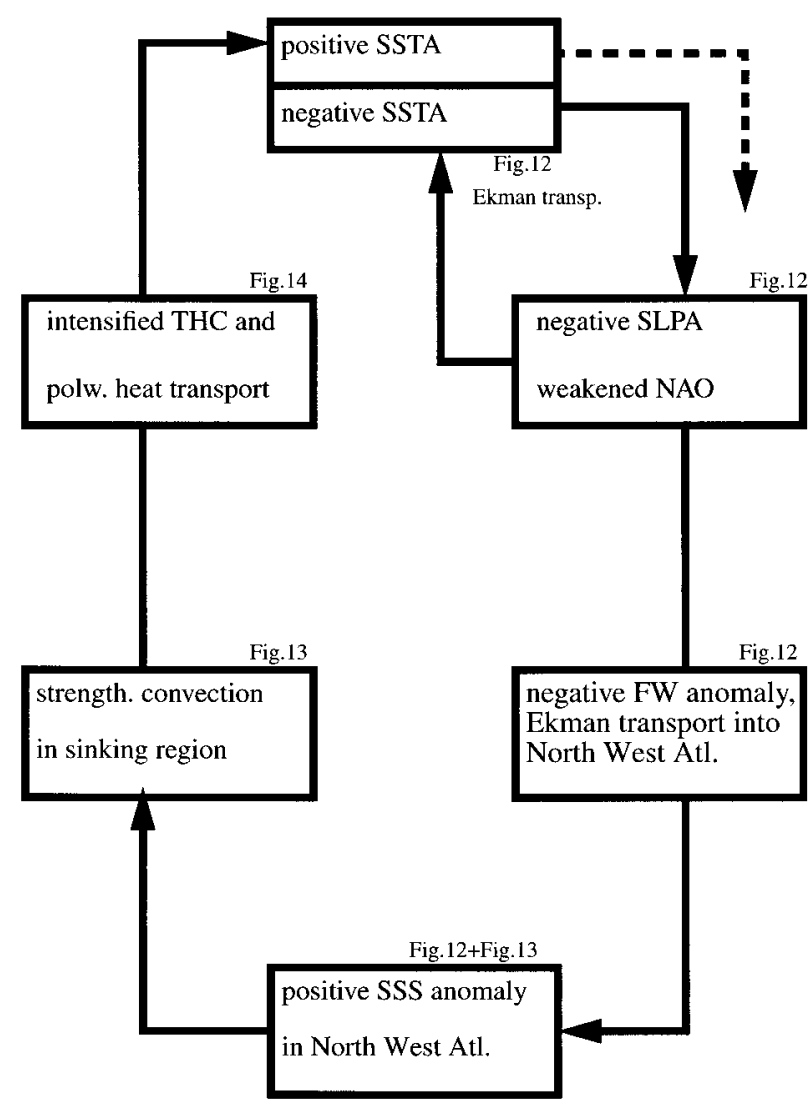

FIG. 20. Schematic diagram of the interactions that lead to the interdecadal cycle. Consider a negative SSTA in the North Atlantic. The atmospheric response to this SSTA involves a weakened North Atlantic Oscillation, causing anomalous freshwater fluxes and Ekman transport off Newfoundland and in the Greenland Sea. This leads to the generation of positive SSS anomalies. These SSS anomalies enhance deep convection in the oceanic sinking regions and subsequently the strength of the THC and the poleward heat transport. This leads to the formation of positive SST anomalies, which completes the phase reversal.

pothesized in the previous sections, we performed atmosphere-only response experiments. A reference state was obtained by forcing the atmosphere model for 30 years with the SST annual cycle from the coupled control integration, and a 10-yr experiment was conducted in which a Northern Hemispheric SSTA is superimposed on the annual cycle. The SSTA forcing field used is shown in Fig. 22a. It has a close resemblance with the Northern Hemispheric SSTA associated with our 35-yr climate mode, as shown in its maximal phase $($ lag +5$)$ in Fig. 22b for a 5-Sv change in the THC. The response of the 500-hPa height anomalies to the SSTA, as simulated in the forced atmosphere-only experiment, is depicted in Fig. 22c. The model simulates anomalous anticyclones in the Pacific (at $30^{\circ}-60^{\circ} \mathrm{N}$ ) and the Atlantic (at $20^{\circ}-50^{\circ} \mathrm{N}$ ). Over the North Atlantic and parts of Canada anomalous low pressure systems are simulated. This pattern would also contribute to a strong NAO index. Apart from minor differences the 500-hPa re- sponse pattern and the pattern of geopotential height differences at $500 \mathrm{hPa}$ associated with the 35-yr climate mode in the coupled run (Fig. 22d) are very similar. Differences between Figs. 22c and 22d might be due to the fact that the SSTA forcing field (Fig. 22a) is not exactly the same as the SSTA pattern in the coupled run (Fig. 22b). However, we believe that the close largescale correspondence of the two atmospheric patterns is very good proof that in our model the atmosphere responds to midlatitudinal SST anomalies in the way as described in section $4 \mathrm{a}$. One can argue that the structures of the SST anomaly patterns in the North Atlantic and North Pacific are associated with changes in the meridional temperature gradients, which modify the atmospheric baroclinity over both basins. Subsequently, this can change the transient eddy activity, as shown in the modeling study of Palmer and Sun (1985). In their study an atmospheric model is forced by an SSTA located near the polar front (quite similar to our North Atlantic SSTA). The atmospheric response was found to be shifted downstream of the SSTA. Additionally the effect of extratropical thermal forcing of the atmosphere is considered in their investigation. Overall their findings are consistent with our results shown in Figs. 12a, 12b, 15a, $15 \mathrm{~b}$, and 22 . Unstable air-sea interactions are therefore crucial constituents of our 35-yr coupled air-sea mode.

One should note that positive geopotential height anomalies in the subtropics are associated locally with positive SST anomalies and the anomalies in the Greenland/Iceland region always appear to be out of phase to the SST anomalies at $30^{\circ}-50^{\circ} \mathrm{N}$ in the North Atlantic. This relationship can be found also in observations and shall be discussed in section 7 .

\section{Interdecadal variability and greenhouse warming}

In this section we want to return to one of the main questions mentioned in the introduction: the role of interdecadal climate modes to mask the anthropogenic greenhouse warming signal. To find the characteristic Northern Hemispheric pattern of 2-m temperature associated with the interdecadal climate variability in our model, we performed an EOF analysis of the bandpassfiltered (transparent for periods between 20 and 45 years) 2-m temperatures from our 700-yr integration. The first empirical orthogonal function (EOF) explaining $27 \%$ of the variance of the filtered data is displayed in Fig. 23a.

The typical signature of this pattern is a warming over land and some adjacent areas and a cooling in the Aleutian area and in the northwest Atlantic region. It can be regarded as a warming pattern (i.e., positive pattern mean value) that is created by an anomalously strong Northern Hemispheric atmospheric circulation. To compare this pattern to the anthropogenic greenhouse warming pattern, we conducted an EOF analysis of the Northern Hemispheric 2-m temperature 
J.) Regr. HEATCONT. $600 \mathrm{~m} /$ Overt. [Kcm/Sv] $-10 \mathrm{c}$

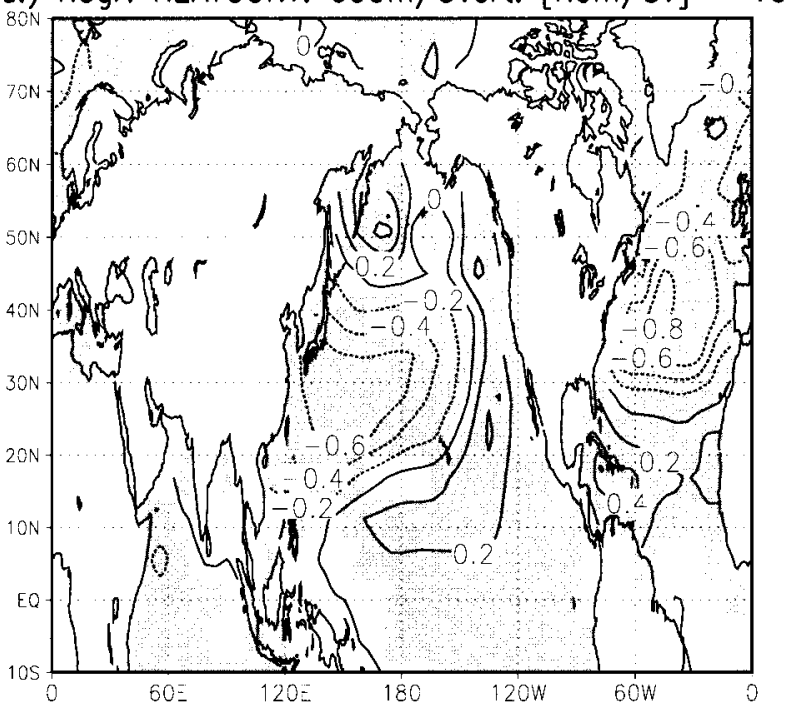

c.) Regr. HEATCONT. $600 \mathrm{~m} /$ Overt. [Kcm/Sv] Oa

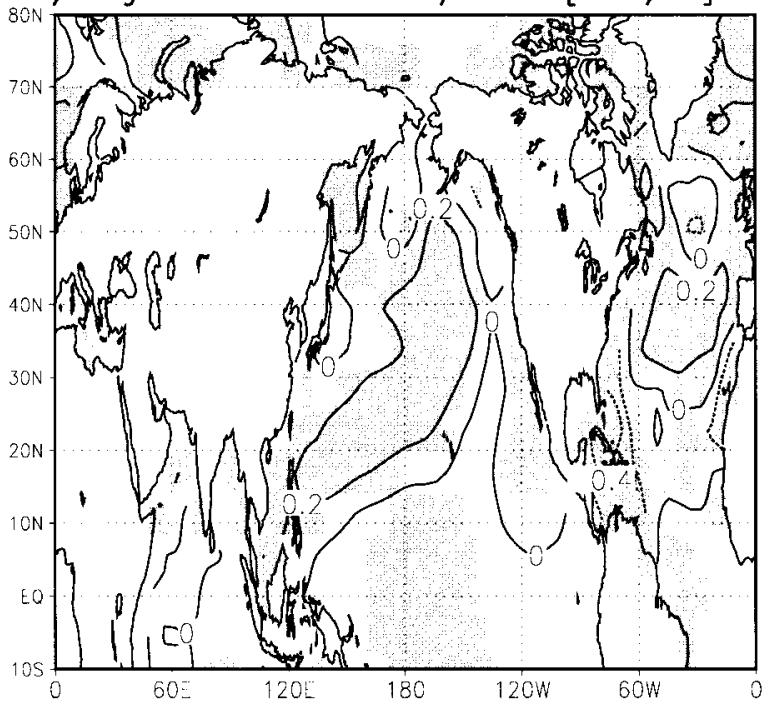

b.) Regr. HEATCONT, $600 \mathrm{~m} /$ Overt. [Kcm $/ \mathrm{Sv}$ ] $-5 \mathrm{a}$

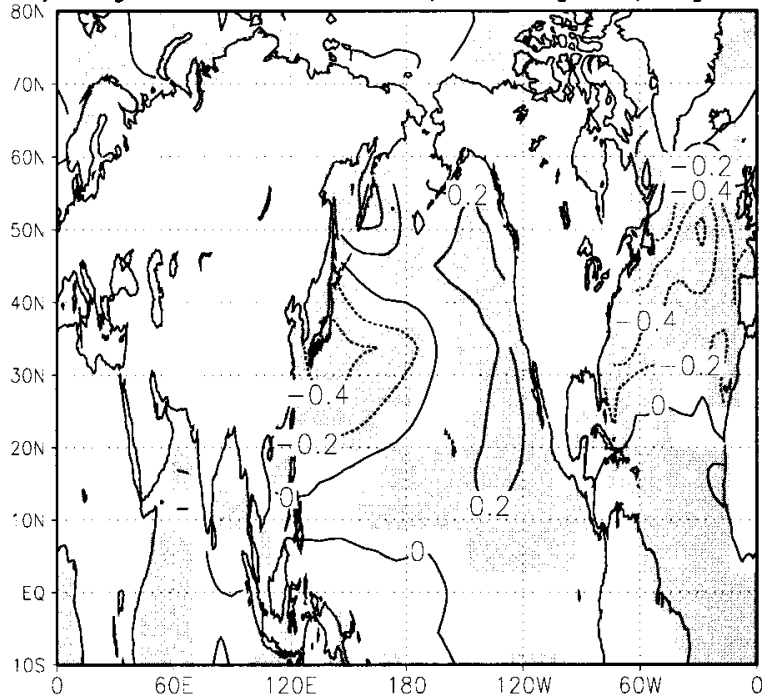

d.) Regr. HEATCONT. $600 \mathrm{~m} /$ Overt. [Kcm/Sv] 50

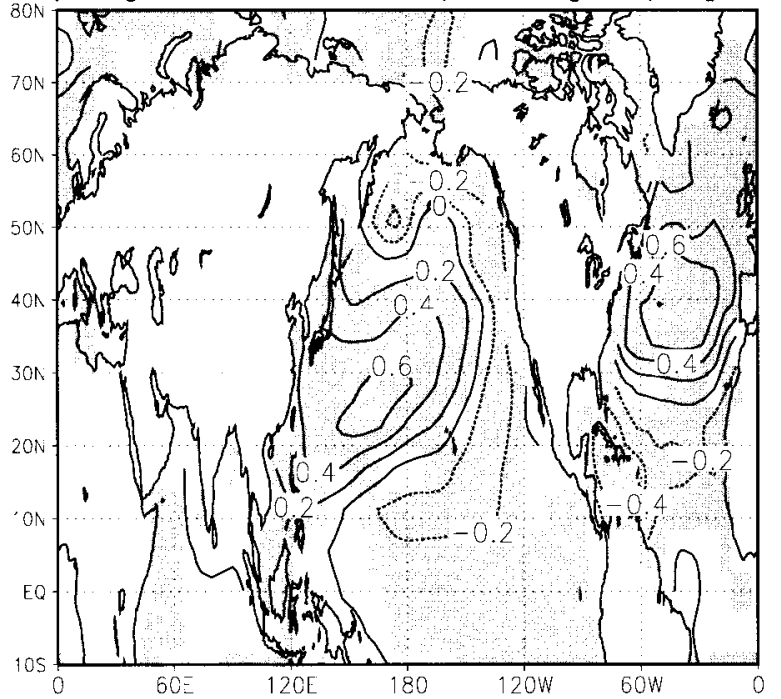

FIG. 21. Lag regression patterns between the bandpass-filtered THC index anomaly and the detrended field anomalies of the oceanic heat content of the upper $575 \mathrm{~m}$ for lags $-10,-5,0$, and $+5 \mathrm{yr}$. Shading indicates nonzero regression with a $95 \%$ confidence limit.

obtained from a 205-yr integration of our model forced by monotonically increasing atmospheric $\mathrm{CO}_{2}$ concentrations (Voss et al. 1997). The $\mathrm{CO}_{2}$ concentrations follow the observed concentrations up to the year 1985 (model year 105) and are subsequently extrapolated following the Intergovernmental Panel on Climate Change scenario A. The first EOF of this $\mathrm{CO}_{2}$ run (Fig. 23b) describes the characteristic warming pattern due to the increasing $\mathrm{CO}_{2}$ concentrations. The corresponding principal component (not shown) exhibits an approximately linear warming trend after the model year 80 (referring to the $\mathrm{CO}_{2}$ emissions of 1960). The warming pattern shows relative minima in the regions of the hemispheric low pressure systems and relative maxima over the continents and the west- ern oceans. It is obvious that the overall structures of the interdecadal pattern and the greenhouse warming pattern are rather similar. To estimate which part of the observed 2-m temperatures evolution can be explained by our interdecadal mode and which part is linked to the modeled anthropogenic greenhouse warming signal, we calculated the projections of the monthly Northern Hemispheric 2-m temperatures observed since 1854 (Jones et al. 1991) onto the two EOF patterns. The results are displayed in Figs. 24a,b. To give an estimate of natural model climate variability, the $\pm 95 \%$ model confidence limit is calculated from the projection of the 2-m temperatures of our 700 -yr control integration onto the greenhouse warming pattern. The results reveal that from the late 1970 s 


\section{a. SSTA FORCING}
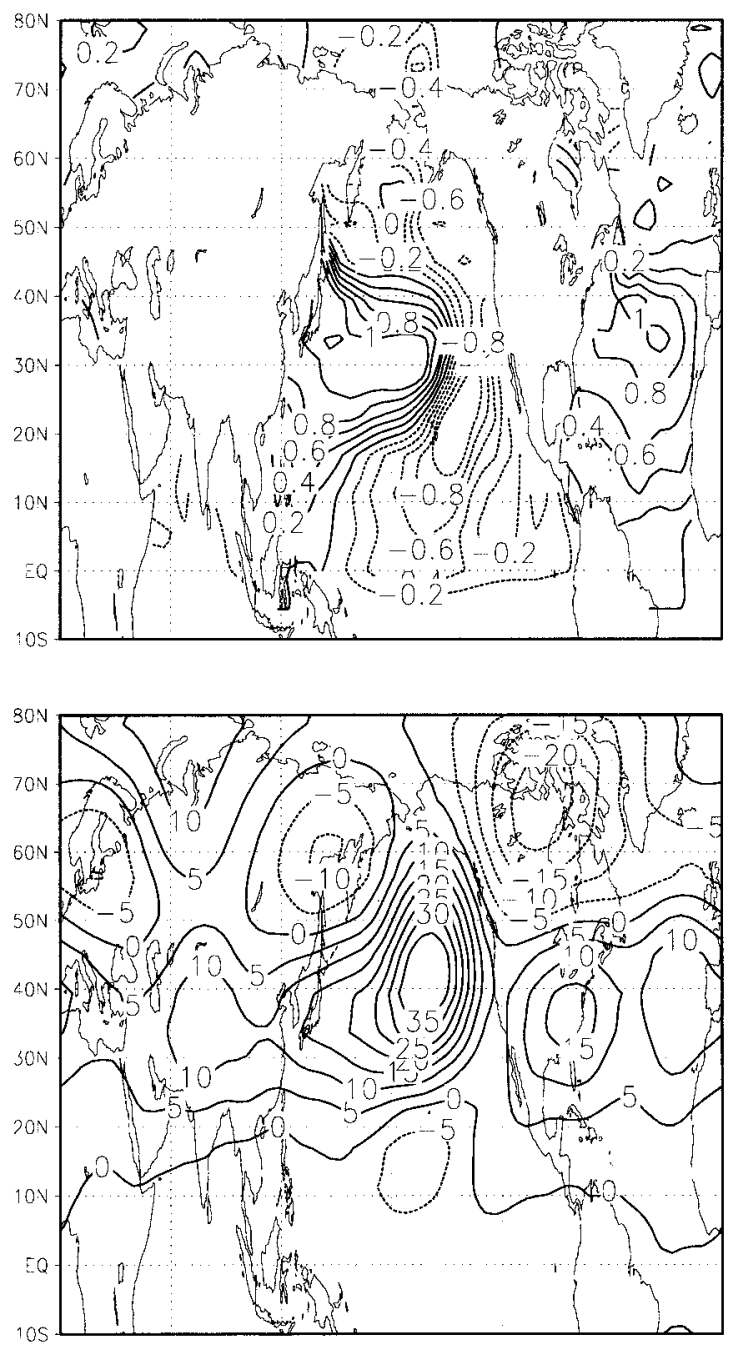

b. REGR. OVT./SSTA K/5Sv
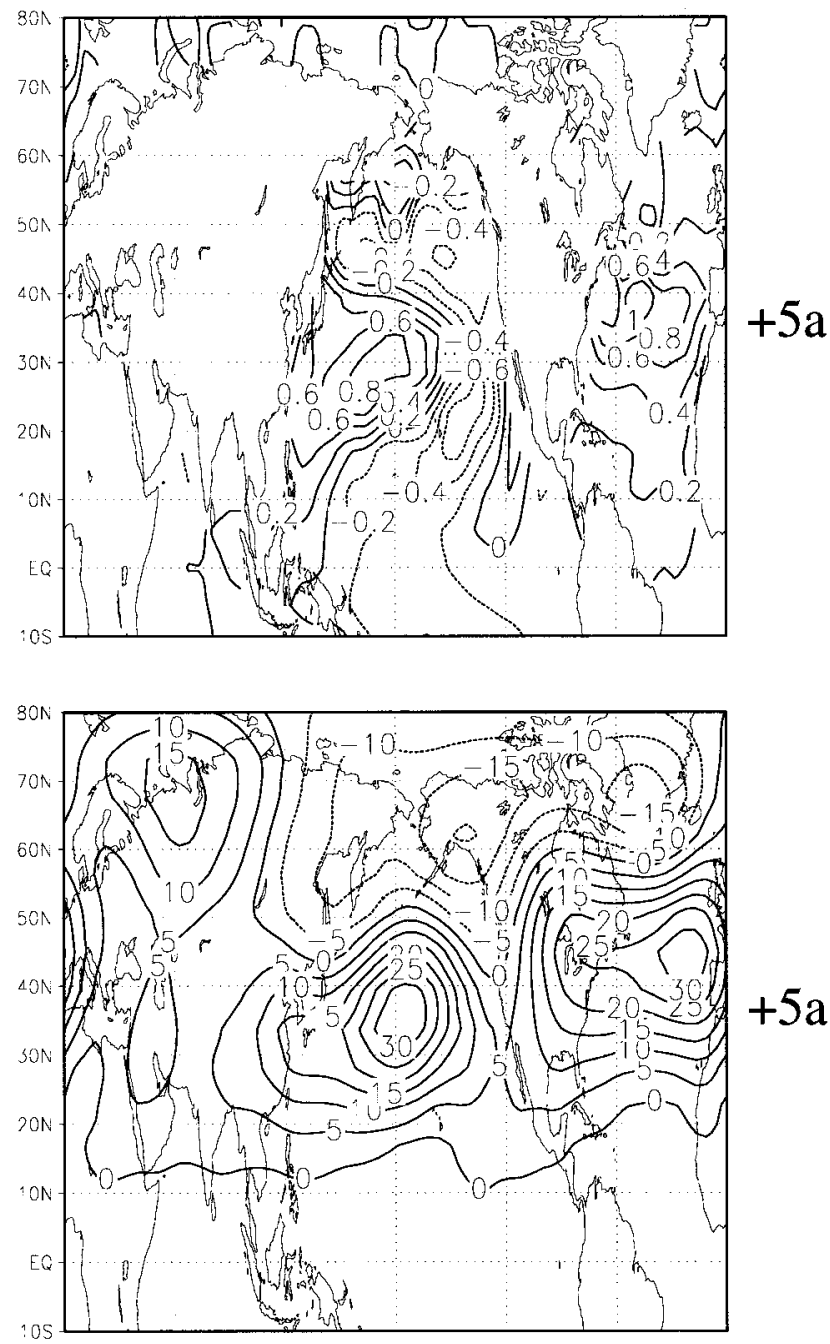

\section{c. 500hPa GPH RESPONSE}

\section{d. REGR. OVT./500hPa GPH m/5Sv}

FIG. 22. (a) SST anomaly pattern that was added to the mean annual cycle for the atmosphere-only response experiment. (b) Lag regression between the bandpass-filtered THC index and the SST anomalies at lag $+5\left(0.2 \mathrm{~K} \mathrm{~Sv}^{-1}\right)$ for a 5-Sv change in the THC. (c) Mean atmospheric 500-hPa geopotential height response to the SSTA pattern of (a). This pattern is obtained by subtracting the mean of the control experiment (30-yr annual cycle forcing) from the mean pattern of the response experiment (10-yr annual cycle + anomaly forcing). (d) Lag regression between the bandpass-filtered THC index and the 500-hPa geopotential height anomalies at lag $+5\left(0.2 \mathrm{~m} \mathrm{~Sv}^{-1}\right) \mathrm{for}^{2} 5-\mathrm{Sv}_{\mathrm{s}}$ change in the THC.

onward the similarity between the observed temperature anomalies and the greenhouse pattern increased strongly, with a 9-yr oscillation superimposed (Fig. 24a). Moreover, the projection of the observed temperatures onto the pattern of the interdecadal coupled atmosphere-ocean mode shows also an increasing tendency since 1970, which correlates extremely well with the wintertime values of the observed NAO index (Fig. 24b). The 9-yr oscillation is visible in all projections shown. Thus, a considerable part of the observed Northern Hemispheric warming is due to an intensification of the Northern Hemispheric circulation since the 1970s. A further amplification of the warming signal by a factor of 2 can be achieved by projecting the observations onto the pattern that is expected from a global warming simulation. Thus, about $50 \%$ of the recent warming can be explained by a pattern that is related to "natural model variability" and corresponds physically to an intensified Northern Hemispheric circulation. This is consistent with the findings of van Loon and Rogers (1978), Hurrel (1995), and Wallace et al. (1995). However, 


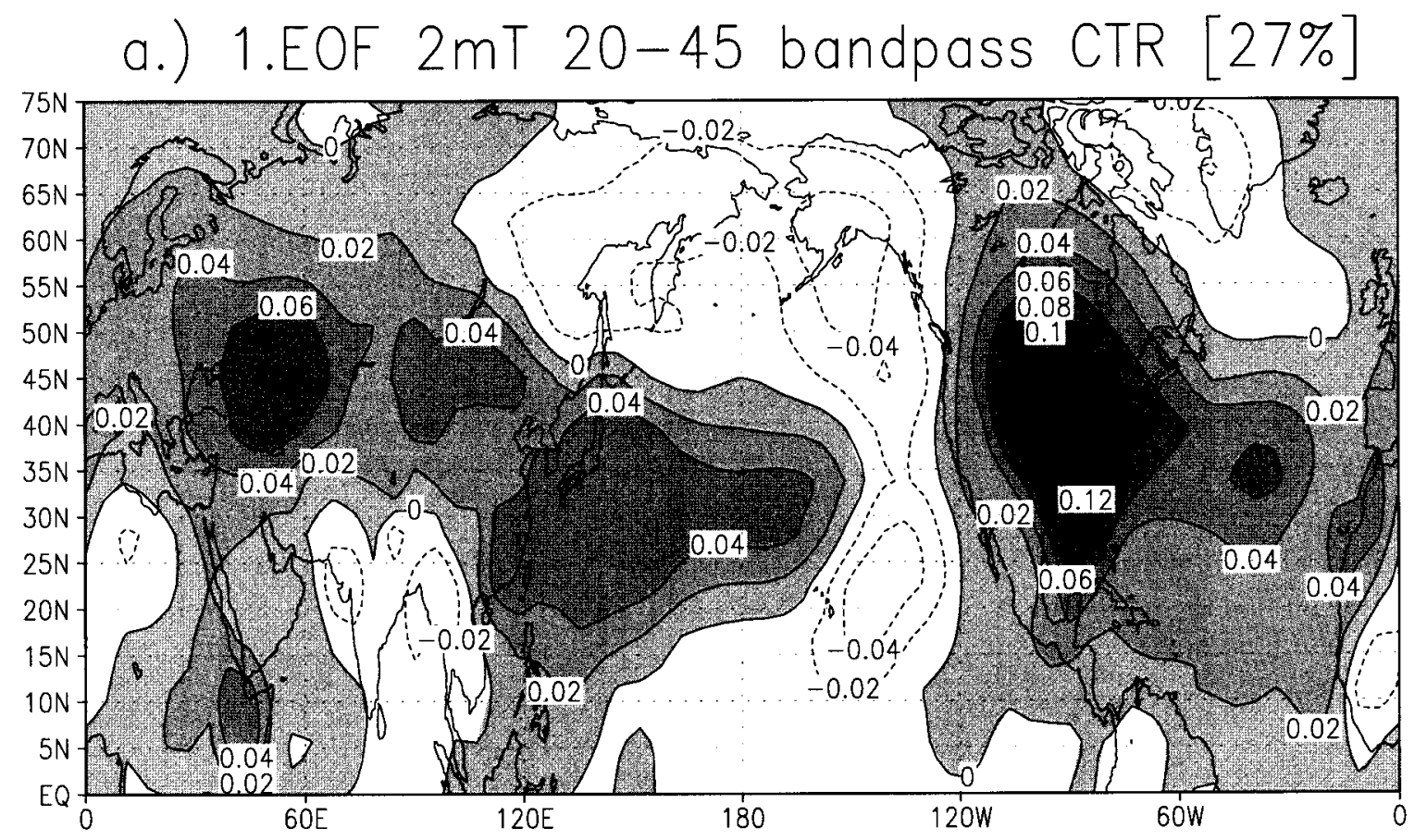

b.) 1.EOF $2 \mathrm{mT} \mathrm{CO} 2$

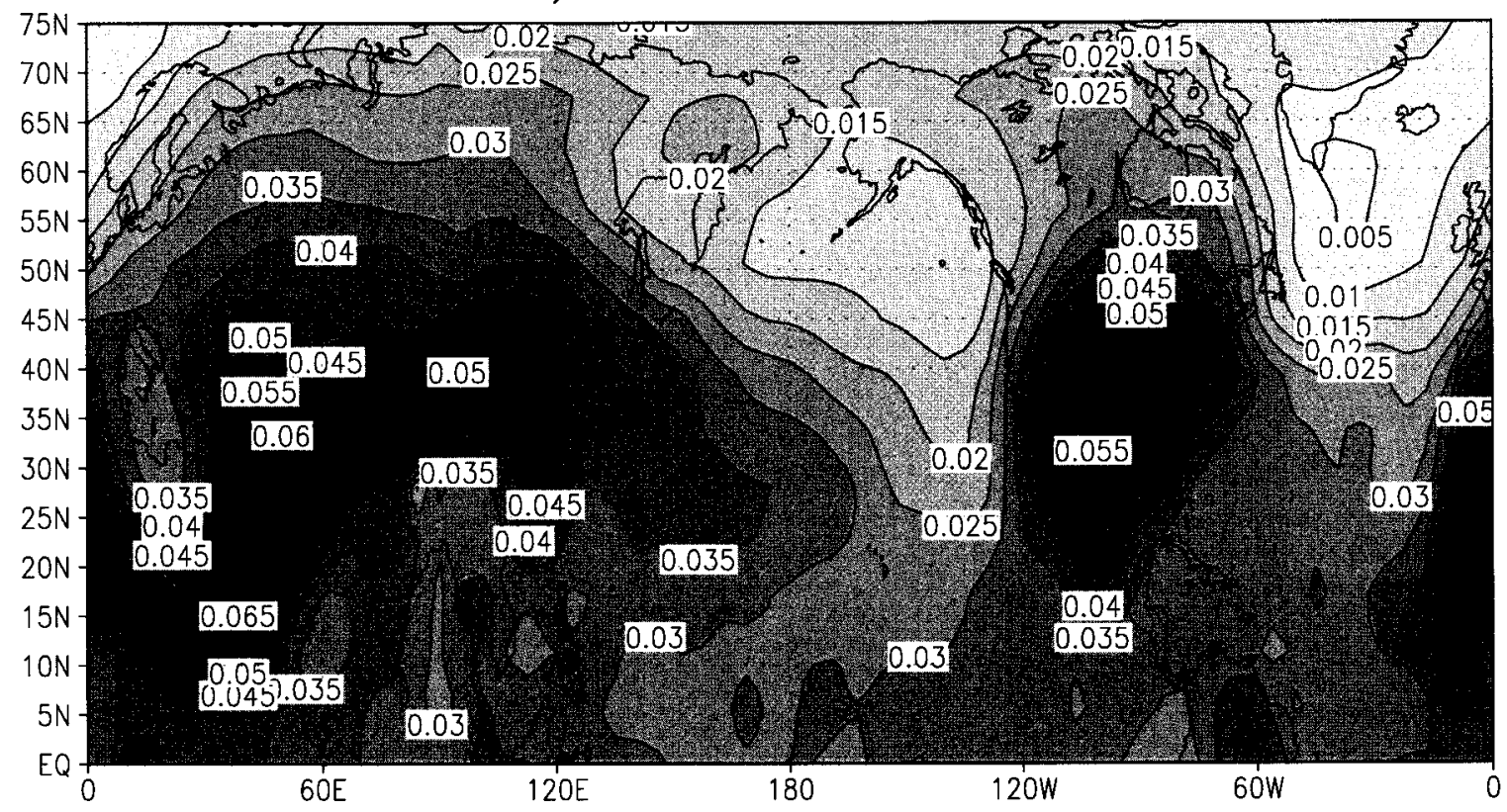

FIG. 23. (a) The 1.EOF pattern of the bandpass-filtered (20-45 yr) 2-m temperatures obtained from the 700-yr control integration. (b) The 1.EOF pattern of the $2-\mathrm{m}$ temperatures obtained from a transient greenhouse warming-simulation. 

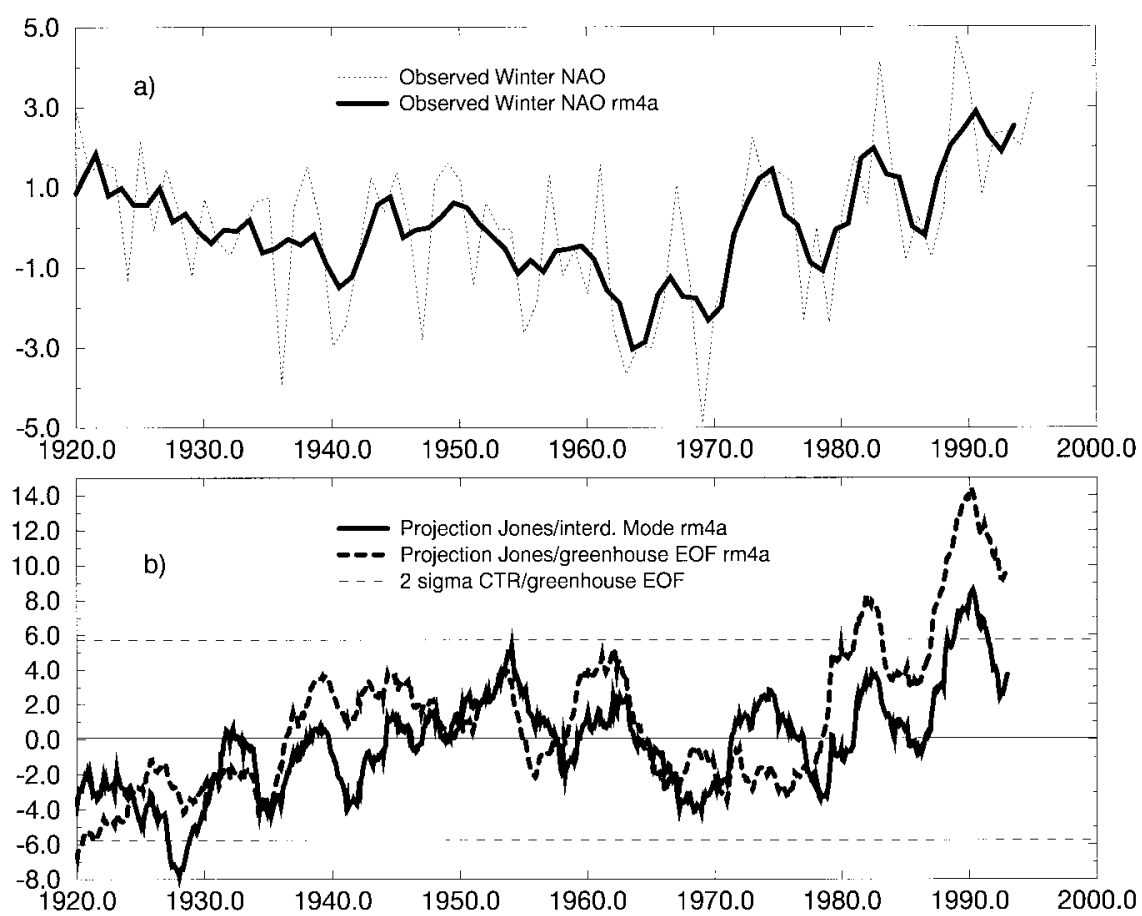

Fig. 24. (a) Observed wintertime North Atlantic Oscillation index (thin). The thick line represents the filtered NAO index. A 4-yr running mean filter was adopted. (b) Projection of the observed 2-m temperatures on the EOFs in Figs. 23a and 23b, respectively. The $\pm 95 \%$ confidence limit for the projection of the control run 2-m temperatures in Fig. 22b is marked by thin dashed lines.

the fact that a strong coupling between the Pacific North American (PNA) and NAO patterns was observed in this century only during the last three decades could be understood also by assuming that anthropogenic greenhouse warming leads to an intensification of the circulation patterns. Changes in the meridional SST gradients as expected from global warming scenarios could lead to modifications in the global atmospheric circulation and hence to changes of the storm-track characteristics. An analysis of historical tree ring data, serving as proxy indexes of the PNA and NAO could give further insights into this matter.

However, one should keep in mind that our model simulation has many caveats, for example, the poor Gulf Stream representation, and the comparison between interdecadal variability and greenhouse warming made here should be interpreted with caution.

\section{Summary and discussion}

This study represents an attempt to understand the mechanisms that generate interdecadal climate variability in the Northern Hemisphere by means of a coupled ocean-atmosphere general circulation model. Our results indicate that atmosphere-ocean interactions involving the thermohaline circulation in the North Atlantic and upper ocean in the North Pacific can generate a low-frequency climate oscillation with a dominant pe- riod of about 35 years. Our investigations focus mainly on the North Atlantic region. The analysis of the anomaly patterns of atmospheric pressure, SST, freshwater flux, SSS, oceanic surface currents, and potential energy loss by convection provides the following physical picture of a coupled atmosphere-ocean mode in the North Atlantic. Salinity anomalies are forced through anomalous atmospheric freshwater fluxes and Ekman transport off Newfoundland and in the Greenland Sea. In the model's main sinking region south of Greenland the salinity anomalies are accumulated until the density conditions are favorable to initiate deep convection. With a lag of five years the meridional overturning cell of the North Atlantic adjusts to the new density conditions. An altered northward heat transport is the consquence, in association with the development of surface temperature anomalies in the entire North Atlantic, which in turn change the atmospheric circulation. Consequently, freshwater flux anomalies (created mainly through evaporation) and anomalous Ekman transport force new salinity anomalies with signs just opposite to those simulated initially. This completes one-half cycle of the 35yr climate mode in our CGCM.

However, the physical mechanisms that generate this kind of oscillation are more complex. A synchronous oscillatory behavior of North Atlantic and North Pacific temperatures is simulated. This can be seen as a clear indication that the atmosphere is a necessary component of the interdecadal climate cycle. Unstable air-sea in- 
SLP (Iceland), SSTA (NAtl.)

runmean $10 \mathrm{a}$

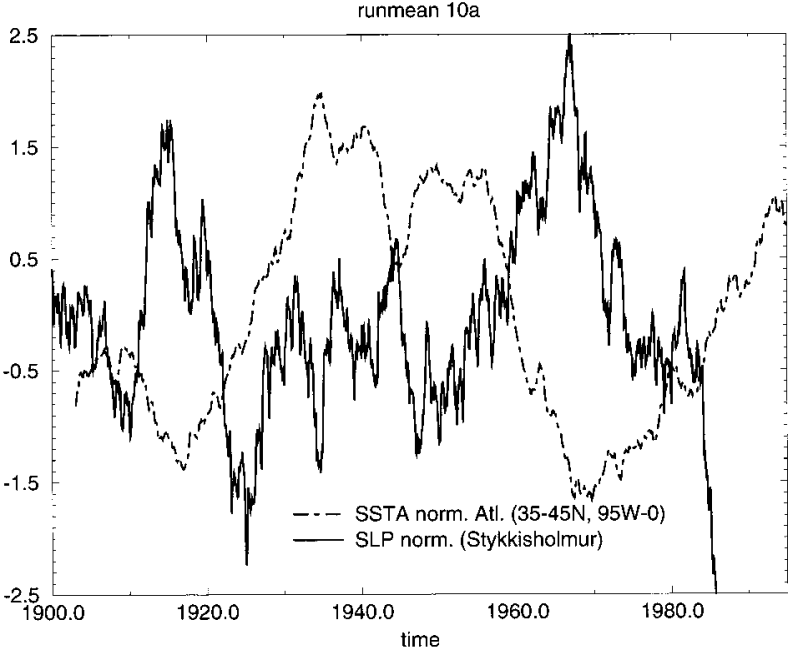

FIG. 25. Normalized and detrended time series of the SLP in Stykkisholmur, Iceland, and the SSTA averaged over the region $95^{\circ} \mathrm{W}$ $0^{\circ} \mathrm{E}$ and $35^{\circ}-45^{\circ} \mathrm{N}$. Both time series are smoothed with 10 -yr running mean filter.

teractions in both oceans seem to play a key role for this oscillation.

It can be argued that some important timescales for this interdecadal mode are provided by the accumulation time for salinity anomalies, the response time of the meridional overturning to salinity anomalies, and the timescale by which the thermal upper-ocean structure lags the THC. Furthermore, the thermal memory of the Pacific can contribute to the timescale of the Northern Hemispheric mode. It is beyond the scope of this CGCM study to deduce whether both oceans provide the memory or whether one of the two oceans only is responsible for the memory. This question is adressed in a forthcoming study.

We have just started to conduct further experiments with our model components, focusing on the atmospheric response to Pacific and/or Atlantic SST anomalies. Another CGCM integration with our model is performed using only prescribed seasonally varying freshwater fluxes (including river runoff), so that the freshwater coupling that was shown to be a contributor to generate salinity anomalies is blocked in this experiment. We are confident that these experiments will shed more light on the interdecadal panoceanic connection found here and may help to determine whether the Atlantic forces the Pacific or vice versa, or whether they constitute a joint oscillator.

Observations seem to also underscore the importance of atmosphere-ocean coupling on interdecadal timescales. Figure 25 shows the normalized and detrended time series of the SLP in Stykkisholmur, Iceland, and of the SSTA averaged over the North Atlantic index region $95^{\circ} \mathrm{W}-0^{\circ} \mathrm{E}$ and $35^{\circ}-45^{\circ} \mathrm{N}$ (obtained from the GISST dataset of the UKMO). A running mean filter of
10 years was used in order to remove annual and interannual variability. Figure 25 shows an anticorrelation between the SLP in Stykkisholmur (Frich et al. 1995) and the SSTA index. This relation is consistent with our model results. Furthermore, there is evidence for a multidecadal timescale in both time series. Therefore, our coupled model feedback loop may explain some of the interdecadal variability observed in the NAO, which was described by D'Arrigo et al. (1993), who analyzed tree ring proxy data. One further prominent example from observations for atmosphere-ocean interactions on interdecadal timescales is the GSA. Common features of our interdecadal model mode and the GSA are a rather strong atmospheric forcing that creates salinity anomalies in the polar and subpolar region, which, after a lag of a few years, change the density conditions in the regions of NADW formation and subsequently modify the strength of the convective overturning. The studies of Greatbach et al. (1991) and Ezer et al. (1995) reveal that between 1955-59 and 1970-74 changes of the thermohaline structure occurred in the North Atlantic in association with the GSA. A very crucial difference between the GSA and the modeled salinity anomalies in the subpolar North Atlantic is the generation mechanism. Whereas in our study, anomalous freshwater fluxes as well as anomalous Ekman transport in the vicinity of a strong surface salinity gradient generate salinity anomalies, the GSA supports the picture that anomalous sea-ice conditions (Häkkinen 1993) and enhanced injection of polar waters into the subpolar gyre (Dickson et al. 1988) are responsible for the birth of the salinity anomaly. However, multidecadal variations like that in our model can be found in nature, for example, in the North Atlantic and the polar climate system. This can be seen in the salinity and temperature time series shown by Dickson et al. (1988) (their Figs. 1 and 29). Furthermore, the feedback loop of Wohlleben and Weaver (1995), explaining the GSA as a manifestation of a coupled air-sea mode, is very similar to our findings. Thus, both the observations and our coupled GCM seem to support the idea that part of the interdecadal variability in the North Atlantic originates from unstable air-sea interactions.

We have shown that the understanding of interdecadal climate variability may be very important to understand the recent observed temperature trends. Further insights into the mechanism of the PNA-NAO coupling and its natural occurrence is required to address the question as to whether the recently observed "dynamic" warming due to the intensified Northern Hemispheric atmospheric circulation is part of the anthropogenic climate change.

Acknowledgments. This work was supported under contract by the European Community under Grant No. EV5V-CT94-0538 (DG 12 DTEE) and the German government under Grant No. 07VKV01/1 and the NOAA Consortium. We are grateful to E. J. Førland and I. 
Hanssen-Bauer for generously providing the North Atlantic Climatological Dataset. Thanks to Drs. E. MaierReimer, Y. Kushnir, T. Delworth, M. Dima, G. Hegerl, and G. Lohmann for fruitful discussions.

\section{REFERENCES}

Benzi, R., A. Sutera, and A. Vulpiani, 1982: Stochastic resonance in climatic change. Tellus, 34, 10-16.

Bjerknes, J., 1964: Atlantic air-sea interaction. Advances in Geophysics, Vol. 10, Academic Press, 1-82.

Broecker, W. S, D. M. Peteet, and D. Rind, 1985: Does the oceanatmosphere system have more than one stable mode of operation? Nature, 315, 21-26.

Cai, W., J. Syktus, H. B. Gordon, and S. O'Farrell, 1997: Response of a global coupled ocean-atmosphere-sea ice climate model to an imposed North Atlantic high-latitude freshening. J. Climate, 10, 929-948.

Cubasch, U., G. C. Hegerl, R. Voss, J. Waszkewitz, and T. J. Crowley, 1997: Simulation with an O-AGCM of the influence of variations of the solar constant on the global climate. Climate Dyn., 13, $757-767$.

D’Arrigo, R. D., E. R. Cook, G. C. Jacoby, and K. R. Briffa, 1993: NAO and sea surface temperature signatures in tree-ring records from the North Atlantic sector. Quart. Sci. Rev., 12, 431-440.

Delworth, T. L., S. Manabe, and R. J. Stouffer, 1993: Interdecadal variations of the thermohaline circulation in a coupled oceanatmosphere model. J. Climate, 6, 1993-2011.

Deser, C., and M. L. Blackmon, 1993: Surface climate variations over the North Atlantic Ocean during winter: 1900-1989. J. Climate, 6, 1743-1753.

Dickson, R. R., H. H. Lamb, S.-A. Malmberg, and J. M. Colebrook, 1975: Climate reversal in the northern North Atlantic. Nature, 256, 479-481.

— J. Meincke, S.-A. Malmberg, and A. J. Lee, 1988: The "great salinity anomaly" in the northern Atlantic 1968-1982. Progress in Oceanography, Vol. 20, Pergamon Press, 103-151.

— - J. Lazier, J. Meincke, and P. Rhines, 1996: Decadal Climate Variability: Dynamics and Predictability. Vol. 1, Global Environmental Change, NATO ASI Series, Springer, 211-259.

Duplessy, J. C., L. Labeyrie, M. Arnold, M. Paterne, J. Duprat, and T. C. E van Weering, 1992: North Atlantic sea-surface salinity and abrupt climate changes. Nature, 358, 485-488.

Ezer, T., G. L. Mellor, and R. J. Greatbach, 1995: On the interpentadal variability of the North Atlantic Ocean: Model simulated changes in transport, meridional heat flux and coastal sea level between 1955-1959 and 1970-1974. J. Geophys. Res., 100, 10559 10566.

Frich, P., and Coauthors, 1995: North Atlantic Climatological Dataset (NACD)-Final national reports 1993-1995. DMI Tech. Rep. 95-16, Danish Meteorological Institute.

Greatbach, R. J., and S. Zhang, 1994: An interdecadal oscillation in an idealized ocean basin forced by constant heat flux. J. Climate, 8, 81-91.

— A. F. Fanning, A. D. Goulding, and S. Levitus, 1991: A diagnosis of interpentadal circulation changes in the North Atlantic. J. Geophys. Res., 96, 22 009-22 023

Griffies, S. M., and E. Tziperman, 1995: A linear thermohaline oscillator driven by stochastic atmospheric forcing. J. Climate, $\mathbf{8}$, $2440-2453$.

Grötzner, A., M. Latif, and T. P. Barnett, 1998: A decadal climate cycle in the North Atlantic Ocean as simulated by the ECHO coupled GCM. J. Climate, 11, 831-847.

Häkkinen, S., 1993: An arctic source for the great salinity anomaly: A simulation of the arctic ice-ocean system for 1955-1975. J. Geophys. Res., 98 (C9), 16 397-16 410.

Hasselmann, K., 1976: Stochastic climate models. Part I: Theory. Tellus, 28, 473-485.
, 1993: Optimal fingerprints for the detection of time dependent climate change. J. Climate, 6, 1957-1971.

— , and Coauthors, 1995: Detection of anthropogenic climate change using a fingerprint method. Proc. Modern Dynamical Meteorology, Symp. in Honor of Aksel Wiin-Nielsen, Reading, United Kingdom, ECMWF, 203-221.

Hegerl, G. C., H. von Storch, K. Hasselmann, B. D. Santer, U. Cubasch, and P. D. Jones, 1996: Detecting greenhouse gas-induced climate change with an optimal fingerprint method. J. Climate, 9, 2281-2306.

Hurrel, J. W., 1995: Decadal trends in the North Atlantic Oscillation: Regional temperatures and precipitation. Science, 169, 676-679.

James, I. N, and P. M. James, 1989: Ultra-low-frequency variability in a simple atmospheric circulation model. Nature, 342, 53-55.

Jones, P. D., T. M. Wigley, and G. Farmer, 1991: Marine and land temperature data sets: A comparison and a look at recent trends. Greenhouse-Gas-Induced-Climatic Change: A Critical Appraisal of Simulations and Observations, M. E. Schlesinger, Ed., Elsevier Science, 593-602.

Kushnir, Y., 1994: Interdecadal variations in the North Atlantic sea surface temperature and associated atmospheric conditions. $J$. Climate, 7, 141-157.

Latif, M., and T. P. Barnett, 1994: Causes of decadal climate variability over the North Pacific and North America. Science, 266, 634-637.

— North America: Dynamics and predictibility. J. Climate, 9, 2407-2423.

— A. Arötzner, M. Münnich, E. Maier-Reimer, S. Venzke, and T. P. Barnett, 1996: Decadal Climate Variability: Dynamics and Predictability. Vol. 1, Global Environmental Change, NATO ASI Series, Springer, 264-292.

Lau, K.-M., and H. Weng, 1995: Climate signal detection using wavelet transform: How to make a time series sing. Bull. Amer. Meteor. Soc., 76, 2391-2402.

Lazier, J. R. N., 1988: Temperature and salinity changes in the deep Labrador Sea, 1962-1986. Deep-Sea Res., 35, 1247-1253.

Levitus, S., 1982: Climatological Atlas of the World Ocean. National Oceanic and Atmospheric Administration, 173 pp. + 17 microfiche.

Maier-Reimer, E., and U. Mikolajewicz, 1989: Experiments with an OGCM on the cause of the Younger Dryas. MPI Rep. 39. [Available from Max-Planck-Institut für Meteorologie, Bundesstr. 55, 20146 Hamburg, Germany.]

— _ _ - and K. Hasselmann, 1993: Mean circulation of the Hamburg LSG model and its sensitivity to the thermohaline surface forcing. J. Phys. Oceanogr., 23, 731-757.

Manabe, S., and R. J. Stouffer, 1995: Simulation of abrupt climate change induced by freshwater input to the North Atlantic Ocean. Nature, 378, 165-167.

Mann, M. E., J. Park, and R. S. Bradley, 1995: Global interdecadal and century-scale climate oscillations during the past five centuries. Nature, 378, 266-270.

Marotzke, J., and P. Stone, 1995: Atmospheric transports, the thermohaline circulation, and flux adjustments in a simple coupled model. J. Phys. Oceanogr., 25, 1350-1364.

Mikolajewicz, U., and E. Maier-Reimer, 1990: Internal secular variability in an ocean general circulation model. Climate Dyn., 4, 145-156.

Mysak, L. A., D. K. Manak, and R. F. Marsden, 1990: Sea-ice anomalies observed in the Greenland and Labrador Seas during 19011984 and their relation to an interdecadal Arctic climate cycle. Climate Dyn., 5, 111-133.

, T. F. Stocker, and F. Huang, 1993: Century-scale variability in a randomly forced, two-dimensional thermohaline ocean circulation model. Climate Dyn., 8, 103-116.

Nakamura, M., P. Stone, and J. Marotzke, 1994: Destabilizing the thermohaline circulation by atmospheric eddy transports. J. Climate, 7, 1870-1882.

Palmer, T. N., and Z. Sun, 1985: A modelling and observational study 
of the relationship between sea-surface temperature anomalies in the north-west Atlantic and the atmospheric general circulation. Quart. J. Roy. Meteor. Soc., 111, 947-975.

Robertson, A. W., 1996: Interdecadal variability over the North Pacific in a multi-century climate simulations. Climate Dyn., 12, $227-241$

Roeckner, E., and Coauthors, 1992: Simulation of the present-day climate with the ECHAM model: Impact of model physics and resolution. Tech. Rep. 93, MPI, 171 pp. [Available from MaxPlanck-Institut für Meteorologie, Bundesstr. 55, 20146 Hamburg, Germany.]

Sausen, R., R. K. Barthels, and K. Hasselmann, 1988: Coupled oceanatmosphere models with flux correction. Climate Dyn., 2, 154163.

Schiller, A., U. Mikolajewicz, and R. Voss, 1997: The stability of the thermohaline circulation in a coupled ocean-atmosphere general circulation model. Climate Dyn., 13, 325-347.

Schlesinger, M. E., and N. Ramankutty, 1994: An oscillation in the global climate system of period $65-70$ years. Nature, $\mathbf{3 6 7}, 723-$ 726.

Spall, M. A., 1993: Variability of sea surface salinity in stochastically forced systems. Climate Dyn., 8, 151-160.

van Loon, H., and J. Rogers, 1978: The seesaw in winter temperatures between Greenland and northern Europe. Part I: General description. Mon. Wea. Rev., 106, 303-309.

Voss, R., R. Sausen, and U. Cubasch, 1998: Periodically synchronously coupled integrations with the atmosphere-ocean general circulation model ECHAM3/LSG. Climate Dyn., 14, 249-266.

Wallace, J. M., Y. Zhang, and J. A. Renwick, 1995: Dynamical contribution to hemispheric mean temperature trends. Science, 270, 780-783.

Weaver, A. J., and E. S. Sarachik, 1991: Evidence for decadal variability in an ocean general circulation model: An advective mechanism. Atmos.-Ocean, 29, 197-231.

— J. Jarotzke, P. F. Cummins, and E. S. Sarachik, 1993: Stability and variability of the thermohaline circulation. J. Phys. Oceanogr., 23, 36-90.

- S. M. Aura, and P. G. Myers, 1994: Interdecadal variability in an idealized model of the North Atlantic. J. Geophys. Res., 99, 12 423-12 442.

Weisse, R., U. Mikolajewicz, and E. Maier-Reimer, 1994: Decadal variability of the North Atlantic in an ocean general circulation model. J. Geophys. Res., 89, 12 411-12 421.

Winton, M., and E. S. Sarachik, 1993: Thermohaline oscillations induced by strong steady salinity forcing of ocean general circulation models. J. Phys. Oceanogr., 23, 1389-1410.

Wohlleben, T. M. H., and A. J. Weaver, 1995: Interdecadal variability in the subpolar North Atlantic. Climate Dyn., 11, 459-467. 